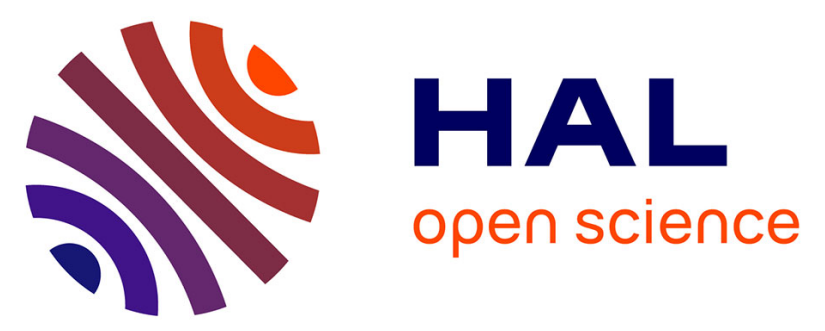

\title{
Halloysite nanotubes (HNTs)/polymer nanocomposites: thermal degradation and flame retardancy
}

\author{
Henri Vahabi, Rodolphe Sonnier, Aurelie Taguet, Belkacem Otazaghine, \\ Mohammad Reza Saeb, Günter Beyer
}

\section{- To cite this version:}

Henri Vahabi, Rodolphe Sonnier, Aurelie Taguet, Belkacem Otazaghine, Mohammad Reza Saeb, et al.. Halloysite nanotubes (HNTs)/polymer nanocomposites: thermal degradation and flame retardancy. Clay Nanoparticles: Properties and Applications, Elsevier, pp.67-93, 2020, 978-0-12-816783-0. 10.1016/B978-0-12-816783-0.00003-7 . hal-02491298

\section{HAL Id: hal-02491298 \\ https://hal.science/hal-02491298}

Submitted on 18 Dec 2020

HAL is a multi-disciplinary open access archive for the deposit and dissemination of scientific research documents, whether they are published or not. The documents may come from teaching and research institutions in France or abroad, or from public or private research centers.
L'archive ouverte pluridisciplinaire HAL, est destinée au dépôt et à la diffusion de documents scientifiques de niveau recherche, publiés ou non, émanant des établissements d'enseignement et de recherche français ou étrangers, des laboratoires publics ou privés. 


\title{
Halloysite nanotubes (HNTs)/polymer nanocomposites: Thermal degradation and flame retardancy
}

\author{
Henri Vahabi ${ }^{1,2^{*}}$, Rodolphe Sonnier ${ }^{3}$, Aurélie Taguet ${ }^{3}$, Belkacem Otazaghine ${ }^{3}$, Mohammad Reza Saeb ${ }^{1,2}$, Günter \\ Beyer $^{4}$ \\ ${ }^{1}$ Université de Lorraine, CentraleSupélec, LMOPS, F-57000 Metz, France \\ ${ }^{2}$ Laboratoire MOPS, CentraleSupélec, Université Paris-Saclay, 57070, Metz, France \\ ${ }^{3}$ Centre des Matériaux des Mines d'Alès (C2MA) - 6, Avenue de Clavières - 30319 Alès Cedex, France \\ ${ }^{4}$ Fire and Polymer, 4700 Eupen, Belgium
}

\begin{abstract}
Clays are inexpensive minerals having outstanding features for engineering applications. Nanosize clays with different shapes and sizes have been widely used in academia and polymer industry alike, so that different angles about the effects of incorporation of nanoclays into polymers have been discussed. Halloysite nanotubes (HNTs) are a class of this family of mineral with outstanding physical properties thanks to the presence of reactive sites in the inner and outer surfaces of nanotubes. Evaluation of thermal behavior and flame retardancy of HNTs, alone or when added as a nanoparticle to a polymer, has been the subject of several reports. Nevertheless, hydrophilic nature of HNTs and their incompatibility with nonpolar polymer matrices was highlighted as an obstacle against proper dispersion of platy and tubular nano-size clays, two main geometrical shapes of nanoclays. This chapter summarizes research done on thermal behavior of clays, particularly HNTs, their chemical affinity as well as thermal and flame properties of their corresponding nanocomposites. The impact of pristine and modified halloysite clays, alone or in combination with other types of additives, on thermal stability and flame retardancy of polymer systems were overviewed in brief.
\end{abstract}

Keywords: Thermal degradation, nanoclay, mineral filler, nanocomposites, flame retardancy, layered silicate, halloysite

Corresponding author:

* Henri VAHABI

Tel.: + 33(0)3 727498 66; Fax: + 33(0)3 879391 01. E-mail address: henr.vahabi@univ-lorraine.fr 


\section{Introduction}

Polymer/layered silicate (PLS) nanocomposites have been in the core of global interest in polymer science and technology because of unique features of them that led to their widespread usage in a wide variety of applications from lab- to industrial scale materialization [1-3]. The outstanding properties of layered silicates, known as clays, made them a promising candidate for many uses to improve mechanical, barrier, thermal and flame retardancy characteristics of various polymers [4-6]. Clay mineral is consisted of tetrahedral sheets of silica joined together with an edge-shared octahedral sheet of alumina with sharing oxygen between interior sheets that make possible cation exchange within the interlayer silicate gallery $[4,7]$. Typically, the sheets in the silicate layers have two forms of crystalline structure, 1:1 layer arrangement (one tetrahedral to one octahedral sheet) like kaolinite and 2:1 structure, like montmorillonite (MMT) as the most important members of clay family [8]. The structures of kaolinite and MMT are illustrated in Figure 1.4.

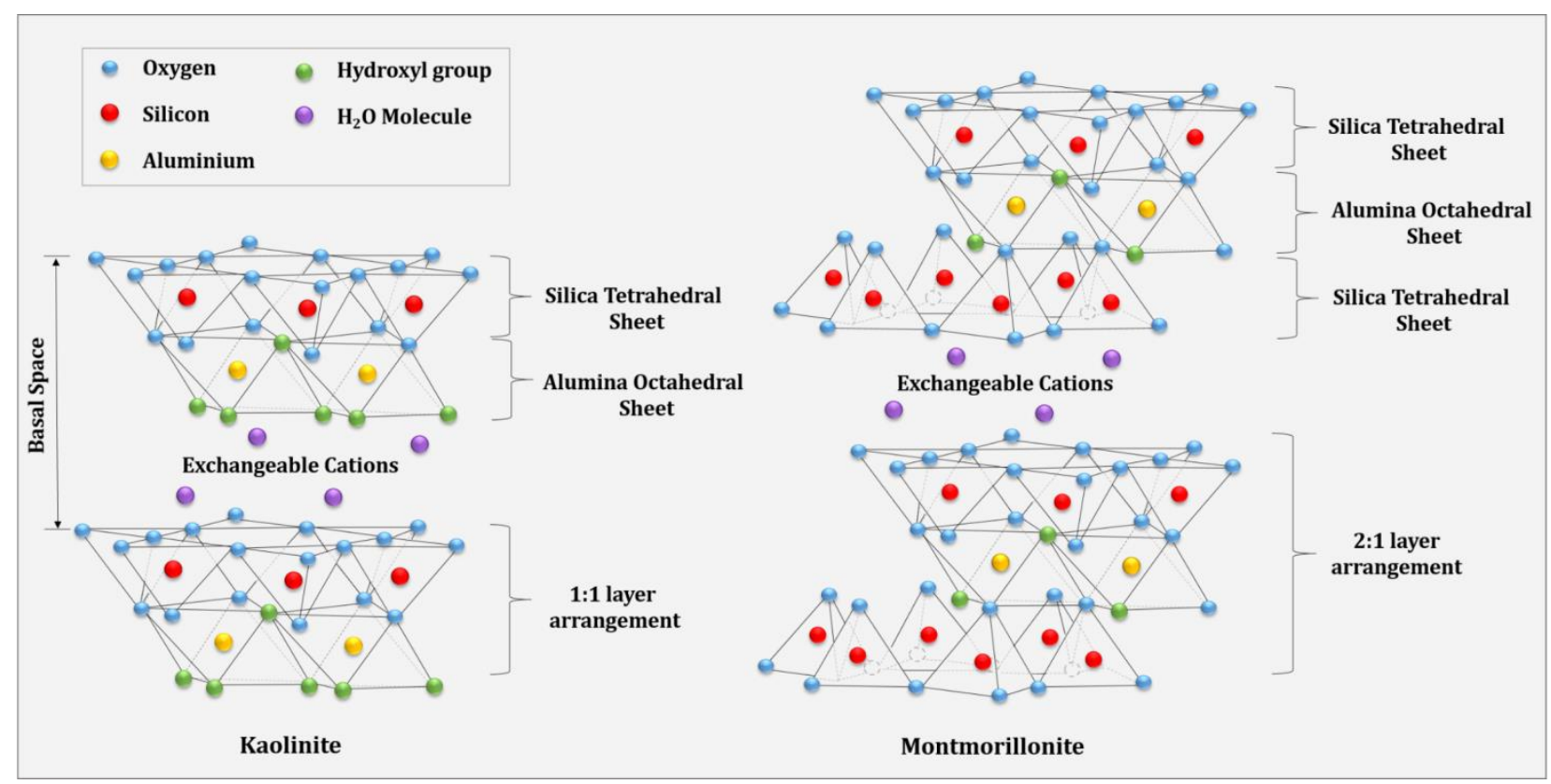

Figure 1.4: Schematic structures of kaolinite and montmorillonite, two possible crystalline forms of clay. 
MMT is the most commonly used clay for preparation of polymer nanocomposite. Intercalation and exfoliation are two possible cases assigned to dispersion state of platelets clays in a polymer matrix, while an intermediate case known as intercalated-and-flocculated has been observed in PLS nanocomposites (Figure 2.4) [9]. There are reliable reports on the dependency of properties of PLS nanocomposites on the state of dispersion of clay into base polymer, a critical key factor determining the performance of system $[10,11]$.

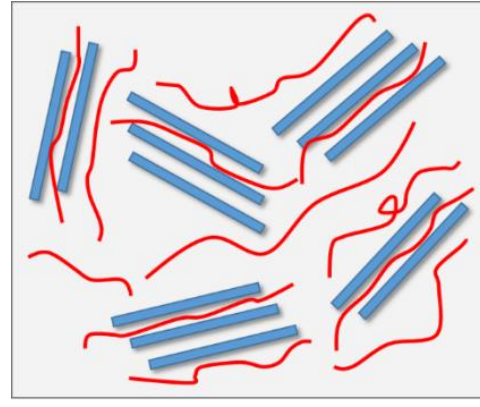

Intercalated

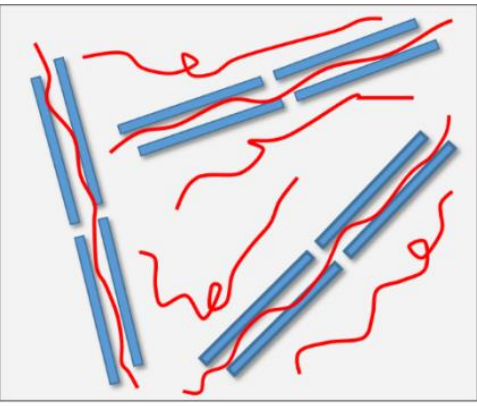

Intercalated-and-Flocculated

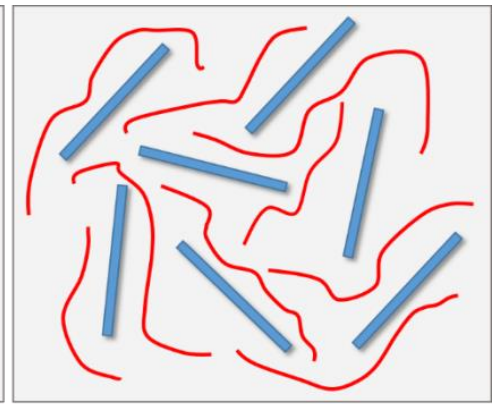

Exfoliated

Polymer Chain

Layered Silicate

Figure 2.4: Schematic representation of possible dispersion states of clay in a typical polymer matrix.

Because of hydrophilic nature of clays and their inherent incompatibility with nonpolar polymer matrices, achieving a proper dispersion of platelet-shape clay minerals in polymers is the focus of global concerns of researchers [12]. Classically, the modification of MMT in order to introduce organic groups and increase the interlayer gallery spacing facilitates dispersion and intercalation/exfoliation of clay and, thereby, enhances the properties and performance of PLS nanocomposites [13]. In this sense, alkyl ammonium salts as organic compounds have been widely used so that a commercially modified clay family denoted as Cloisite entered the market [13]. A wide variety of organic modifiers were practiced to modify montmorillonite, and several functionalized clays were subsequently produced and commercialized by the Southern clay Co., as presented in Table $1.4[14,15]$. 
Table1.4: Organic modifiers used in commercial clays, provided by Southern clay Co. $[15,16]$.

\begin{tabular}{clc}
\hline \multicolumn{1}{c}{ Clay } & \multicolumn{1}{c}{ Organic modifier } & $\begin{array}{c}\text { Modifier concentration } \\
\text { (meq/100 g clay) }\end{array}$ \\
\hline Cloisite 10A & $\begin{array}{l}\text { Dimethyl, benzyl, hydrogenated tallow*, quaternary } \\
\text { ammonium chloride }\end{array}$ & 125 \\
Cloisite 15A & $\begin{array}{l}\text { Dimethyl, dihydrogenated } \\
\text { ammonium chloride }\end{array}$ & 125 \\
Cloisite 20A & $\begin{array}{l}\text { Dimethyl, dihydrogenated } \\
\text { ammonium chloride }\end{array}$ & tallow, quaternary \\
Cloisite 25A & $\begin{array}{l}\text { Dimethyl, hydrogenated tallow, 2-ethylhexyl, } \\
\text { quaternary ammonium methyl sulfate }\end{array}$ & 95 \\
Cloisite 93A & methyl, dihydrogenated tallow, ammonium bisulfate & 90 \\
Cloisite 30B & $\begin{array}{l}\text { Methyl, tallow, bis-2-hydroxyethyl, quaternary } \\
\text { Ammonium chloride }\end{array}$ & 90 \\
\hline
\end{tabular}

*Tallow ( 65\% $\left.\mathrm{C}_{18}, \sim 30 \% \mathrm{C}_{16}, \sim 5 \% \mathrm{C}_{14}\right)$

Melt processing is known as a conventional route to prepare polymer/filler compounds, but a relatively high thermal stability is always needed to prevent thermal decomposition of nanocomposite in the course of melt processing $[16,17]$. The thermogravimetric analysis (TGA) measurements performed on different kinds of platy clays are signifying various types of thermal decomposition behavior for clays in view of differences in the chemistry of alkyl ammonium surfactants used in clay modification $[18,19]$. The onset decomposition temperature of organically-modified clay is about $180^{\circ} \mathrm{C}$, regardless of clay type, but decomposition curve peaks at a temperature somewhere in between 200 and $500{ }^{\circ} \mathrm{C}$ depending on thermal stability of organic surfactants present in clay structure. The complete thermal degradation takes place above $500{ }^{\circ} \mathrm{C}$ due to dehydroxylation of aluminosilicate structure of MMT $[15,20]$. The onset decomposition temperature, the maximum mass loss rate temperature and the residual mass of sodium MMT and commercially available modified MMT are reported in Table 2.4 [15]. 
Table 2.4: TGA characteristics of organically modified platy clay [15].

\begin{tabular}{lccc}
\hline Clay & $\begin{array}{c}\text { Onset decomposition } \\
\text { temperature from TGA }(\mathbf{C})\end{array}$ & $\begin{array}{c}\text { Maximum mass loss rate } \\
\text { temperature from DTG ( } \mathbf{C})\end{array}$ & $\begin{array}{c}\text { Residual mass } \\
\text { (\%) }\end{array}$ \\
\hline Cloisite $\mathbf{N a}^{+}$ & - & - & 95 \\
\hline Cloisite 10A & 160 & $245,310,395$ & 66 \\
\hline Cloisite 15A & 192 & 331,447 & 60 \\
\hline Cloisite 20A & 198 & 336,451 & 63 \\
\hline Cloisite 25A & 192 & 330,390 & 74 \\
Cloisite 93A & 212 & 347 & 76 \\
\hline Cloisite 30B & 174 & 398,427 & 73 \\
\hline
\end{tabular}

Incorporation of a given kind of nanoclay into different polymers may lead to different sorts of thermal behavior changes depending on physical and chemical properties of polymers such as glass transition temperature, molecular weight, chemical structure, and more critically the physical and chemical interaction between clay and polymer chains [21,22]. A platy nanoclay plays the role of thermal barrier or insulator to improve thermal behavior, especially during combustion, of nanocomposites, but it may inversely assist in thermal decomposition through heat accumulation by stacking silicate layers or catalytic effect of hydroxyl groups that accelerate decomposition of polymer chains $[23,24]$. As demonstrated earlier, the dispersion state of clays in polymer matrices determines to a large extent the ultimate properties of PLS nanocomposites. A general agreement is that better dispersion of nanoclays at low loading levels throughout polymers boosts thermal barrier character, while higher loadings can unsurprisingly facilitate thermal decomposition $[25,26]$. Since alkyl ammonium surfactants are unstable at elevated temperatures, their usage makes debate within PLS nanocomposites manufacturing technology-what commercially modified clays suffer from which during melt processing of polymers or later when PLS is utilized in high temperature applications [27]. Functionalization of silicate layer with silane coupling agents is a convenient method to improve the compatibility of clay minerals with polymers. By contrast, once hydroxyl groups on the silicate layer surface are consumed by silanol condensation, the aggregation of the platelet clays can be restricted leading to an improved dispersion of clay layers. In this way, a higher thermal stability is expected for the nanocomposite [28]. 
Even if MMT was very famous and widely used, other types of clay were also considered in polymer science and technology. Halloysite nanotubes (HNTs) has a new yet important position in this regard. $\mathrm{HNTs}, \mathrm{Al}_{2} \mathrm{Si}_{2} \mathrm{O}_{5}(\mathrm{OH})_{4} .2 \mathrm{H}_{2} \mathrm{O}$, are another member of clay family with their special own tubular structure consisting of an outer silica tetrahedral surface layer and an inner alumina octahedral surface that resembles closely to the kaolinite structure (Figure 3.4) [29].

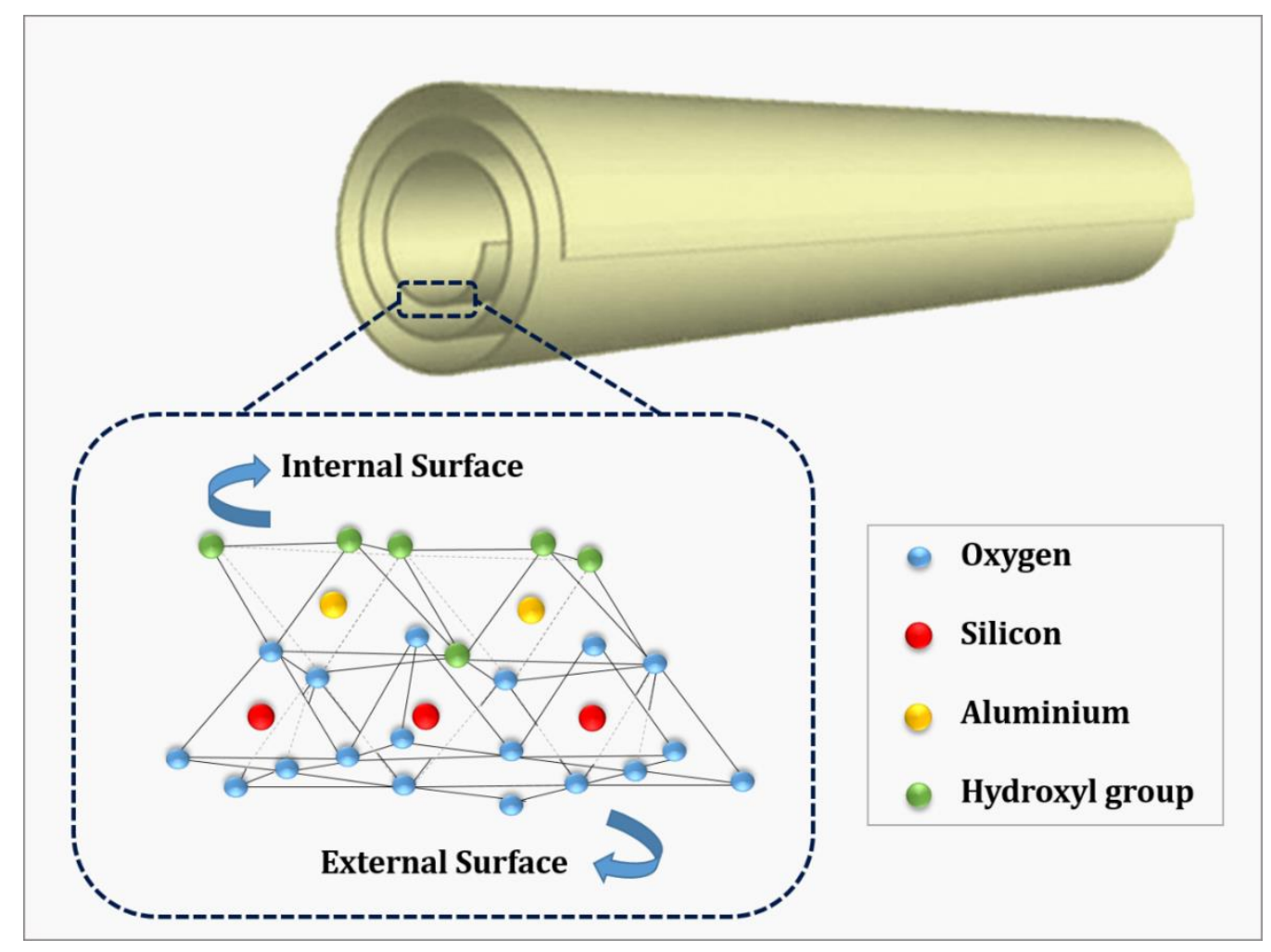

Figure 3.4: Schematic structure of HNT considering inner and outer surfaces and their chemical nature.

Biocompatibility, natural availability, high strength and high thermal stability of HNTs are the main reasons why such nanotubes are becoming the center of research programs in polymer science, especially in nanocomposites [30-32]. In general, tubular structure of HNTs is responsible for facilitated dispersion of HNTs compared to platy clays with their exfoliation character in polymer matrices [33]. Moreover, still comparatively, the little number of hydroxyl groups in the outer surface of HNTs makes dispersion of clay nanotubes in a polymer matrix easier than that of MMT, but tendency to aggregation due to the high surface energy of tubular 
clays is also underlined in some reports [34,35]. Similar to platy clays, dispersion of HNTs plays a key role in the ultimate properties of the resulting polymer nanocomposites such as flame retardancy $[36,37]$. HNTs with their inherent high thermal stability can act as a mass and/or heat barrier against thermal degradation in polymer nanocomposites. In addition, diffusion of polymer chains and degradation components to the lumen of HNTs may assist in enhancement of resistance of nanocomposites to thermal degradation [33]. For example, nanocomposites based on polypropylene (PP) and HNTs were studied, and it was found that thermal stability of nanocomposite was improved by entrapping of volatile components in HNTs lumen $[38,42]$.

The use of HNTs in thermoplastics was the subject of several studies [39-41]. Elsewhere, polyamide 12 (PA12)/HNTs nanocomposites were studied for thermal stability by TGA, where ca. $30^{\circ} \mathrm{C}$ rise in the onset temperature of decomposition was observed at $10 \mathrm{wt} . \%$ HNTs loading [43]. Likewise, HNTs appeared successful in taking credit for their acceptable thermal stability among clay family and positioned on the top of the list of candidates. In epoxy nanocomposites, HNTs functioned as thermal barrier at high temperatures, where there was no obvious effect at initial decomposition [44]. When used in polyurethane (PU), the results revealed that the thermal stability of PU/clay nanocomposite was strongly affected by the dispersion state of silicate layers [45]. However, difficulties were associated with dispersion of HNTs at high loading levels that necessitated surface functionalization of HNTs to achieve the highest possible level of thermal stability.

\section{Effect of raw HNTs on thermal stability and flame retardancy of polymers}

Several reviews have been done in recent years directed at the use of HNTs in polymer systems, particularly for higher flame retardancy purpose $[46,47]$. In their interesting work, Smith et al. [48] used HNTs in layer-by-layer coating to decrease efficiently the flammability of polyurethane foam. The content of halloysite in the coating was around $90 \mathrm{wt} . \%$. Except this work, to the best of our knowledge, raw HNT has been used very little as flame retardant additive incorporated into polymers, including elastomers, polyolefins, polyamides, polyesters, thermosets or blends. 
It is well known that micron-size mineral fillers are not very efficient and need to be incorporated at contents up to $65 \mathrm{wt} . \%$ to guarantee improvement in the flame retardancy. By contrast, some nanoparticles, especially carbon nanotubes (CNTs) and organomodified montmorillonite (OMMT) appeared very effective to reduce the heat release when they were well dispersed, even at very low contents (< 5 wt.\%). Despite its nanoscale dimension, HNTs is not really efficient when it is used alone. Figure 4.4 shows the decrease in peak of heat release rate (pHRR) versus the HNTs content in various polymers. The decrease in pHRR of acrylonitrilebutadiene-styrene (ABS) filled with HNTs measured in cone calorimetry was almost equal to HNTs loading (-29 \% and $-38 \%$ for 20 and 30 wt.\% of HNTs, respectively) [49]. At best, 10 wt.\% of HNTs leads to a fall in pHRR by $40 \%$ and the decrease reaches $69 \%$ for 30 wt.\% filler loading [50]. The HRR curve shape becomes typical of thick-charring behavior (i.e. a slight and continuous decrease in HRR after pHRR and not only a HRR "plateau") only for 30 wt.\% of HNTs incorporation. The performance values are in the same range as those already observed for boehmite nanoparticles, for example in polyamide 11 (PA11) [51], and submicronic kaolinite or micronic aluminum trihydroxide in ethylene-vinyl acetate copolymer (EVA) [52]. It should be considered that $5 \mathrm{wt}$.\% incorporation of well-dispersed layered silicate in EVA allows a decrease of more than $50 \%$ for pHRR [53]. Similarly, Kashiwagi et al. [54] observed a fall in pHRR by $80 \%$ when they incorporated 0.5 wt.\% of well-dispersed multiwalled CNTs in PP, which reflects the superior efficiency of carbon nanotube structures. 


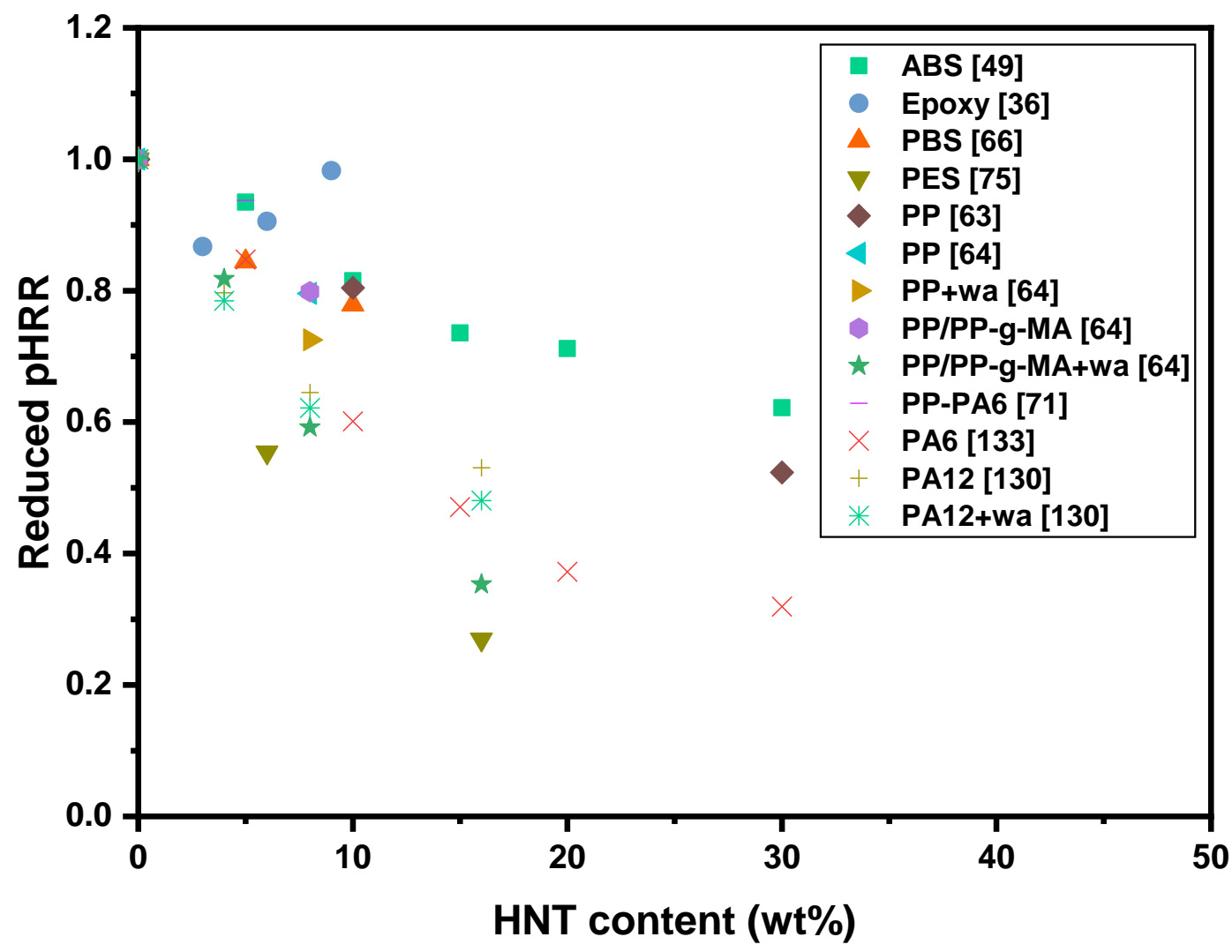

Figure 4.4: Reduced pHRR (in regard with pure polymer) for various polymers filled with HNTs wt.\% (wa: water-assisted extrusion process).

Barrier effect imparted by HNT is due to the tortuous path formed by nanoparticles when accumulation took place on the top surface of the sample during burning. This labyrinthine effect slows down the release of fuels produced by pyrolysis that usually feed the flame. Another kind of barrier effect was observed when nanoparticles enhanced the viscosity of the molten material that could effectively reduce vigorous bubbling and facilitate the formation of protective clay layer. Some correlations have been observed between viscoelasticity at low temperature and fire performance of nanocomposites in cone calorimetry $[52,55,56]$.

Apart from cone calorimetry, some other tests are commonly used by researchers in order to evaluate flame retardancy potential. UL94 rating and limiting oxygen index (LOI) are not significantly improved by HNT. Inuwa et al. [57] reported that 10 wt.\% HNT causes a rise in LOI of a PP/polyethylene terephthalate (PET) blend from 18.3 to 20.3. HNT in ethylene propylene diene monomer rubber (EPDM) allows enhancing UL94 rating, but only at high loadings [58]. 
Reports suggest that $30 \mathrm{phr}$ is needed to reach V2 rating, while $100 \mathrm{phr}$ (i.e. almost 50 wt.\% of the material) leads to V0 rating. The incorporation of up to $10 \mathrm{wt} \%$ of HNT does not improve the UL94 rating of poly(ethylene-co-vinyl acetate-co-carbon monoxide) [59]. However, LOI is slightly improved from 29 to 34. HNT also does not improve the UL94 rating of polyamide 6 (PA6), but LOI is enhanced at high contents of nanoparticle loading [50]. LOI of pure PA6 and PA6 systems filled with 20 and 30 wt.\% of HNTs are 22, 25 and 30, respectively. LOI of epoxy system is slightly improved from 18 to 19.8 in the presence of 20 wt.\% of HNT [60].

Clays often reduce the thermal stability of polymers due to catalytic effect of acid sites formed by decomposition of hydroxyl groups on the halloysite surface. In case of hydrolysable polymers, release of water from halloysite can also be invoked to explain a loss of thermal stability. Nevertheless, in some cases, HNT seems to improve thermal stability (see Table 3.4). For a given polymer, different authors report contradictory tendencies. To explain the improvement of thermal stability, barrier effect and entrapment of volatiles in the lumen are quite often proposed by authors. Nevertheless, in TGA, sample is thermally thin and thermal barrier effect occurrence is far from expectation. Barrier effect to oxygen can occur, but only in aerobic pyrolysis. Entrapment of volatiles in lumen is an assumption which has not been evidenced. Moreover, this phenomenon cannot occur with other clays, for which the improvement of thermal stability is also observed. Wang and Huang [61] have compared the thermal stability of PP filled with low amount of HNT prepared according to two different processes. The first allows to highly orientating HNT and thermal stability is more enhanced, especially in nitrogen than in the case of randomly oriented HNT. The authors noted that barrier effect should be more efficient in the latter. In such cases, the HNT content was too low to entrap significant amount of volatiles. Therefore, the authors considered that the increase in thermal stability was due to direct stabilizing effect relative to interactions between PP chains and HNT surface. These interactions would be especially strong in the case of highly oriented halloysite due to interfacial crystallization. In most cases, raw HNTs has no significant effect on char content, i.e. halloysite is not a char promoter. This conclusion can be drawn from thermogravimetric analysis under nitrogen or cone calorimetry. For example, residue content 
of PA6 filled with halloysite in cone calorimeter test is very close to HNT content, after taking into account the loss of water by dehydration (-15 wt.\%) [50].

Table 3.4: Influence of raw HNT on thermal stability of polymers. " + " means that the thermal stability is improved whereas "-" means that it is reduced.

\begin{tabular}{lccc}
\hline \multicolumn{1}{c}{ Polymer } & Thermal stability & Atmosphere & Reference \\
\hline Polyethersulfone (PES) & + & Nitrogen, air & {$[62]$} \\
PP & + & Nitrogen & {$[63]$} \\
PP & - & Nitrogen & {$[64]$} \\
PA12 & + & Air & {$[65]$} \\
Polybutylene succinate & - & Nitrogen & {$[66]$} \\
(PBS) & + & Nitrogen & {$[49]$} \\
ABS & + & Nitrogen & {$[58]$} \\
EPDM & (+ at very high loading) & Nitrogen & {$[67]$} \\
PET & $=$ & Nitrogen & {$[59]$} \\
EVACO (ethylene-vinyl & $=$ & Nitrogen & {$[68]$} \\
acetate-carbon monoxide) & $=$ & & \\
Polystyrene (PS) & - & & \\
\hline
\end{tabular}

When char is naturally formed by decomposition of polymer, HNT can reinforce it or improve its thermal stability. Nakamura et al. [69] have added 10 wt.\% of HNT into composites based on low-flammability soy protein matrix reinforced with jute fabrics. They reported that HNT did not significantly reduce the main pHRR, but it limits the intensity of the second pHRR occurring at the end of the test, which is normally related to the degradation of the char layer. Some authors have compared the performance of HNT with those of other fillers when they are used alone in polymers. Almost often, HNT appeared less efficient. Vahabi et al. [70] compared the flame retardancy of epoxy resins having low content (3-9 wt.\%) of HNT with that of expandable graphite (EG). From 6 wt.\%, expandable graphite allowed a strong reduction in pHRR because of EG expansion forming an intumescent protective structure. By contrast, HNT did not reduce the flammability as a whole. Elsewhere addition of 15 wt.\% of HNT or sepiolite alone in the PP/PA6 blend led to no significant improvement in the flame retardancy according to cone calorimeter data, while OMMT at the same content had a great effect on pHRR (-46\%) [71]. In another report, 5 or $10 \mathrm{wt} . \%$ of HNT in polybutylene succinate (PBS) led to poor fire performance tracked by cone calorimetry [66]. The pHRR value decreased from $809 \mathrm{~kW} / \mathrm{m}^{2}$ to 683 and then $630 \mathrm{~kW} / \mathrm{m}^{2}$ from neat PBS to PBS/HNT(5 wt.\%) and PBS/HNT(10 wt.\%) samples, respectively. 
Such a fall in pHRR was more significant when HNT was replaced by sepiolite (597 and 314 $\mathrm{kW} / \mathrm{m}^{2}$ for 5 and $10 \mathrm{wt} . \%$ of sepiolite, respectively). Rybinski and Janowska have compared the efficiency of HNT and carbon nanofibers as flame retardants into crosslinked nitrile rubber (NBR) [72]. Based on TGA, LOI and cone calorimeter data, carbon nanofibers were more efficient. According to the authors, this better performance was due to the structure of the carbon layer formed during burning, but also to the radical scavenging activity of carbon nanofibers.

\subsection{Synergism with other flame retardants}

Synergism between raw HNTs and other flame retardants was the subject of hot debates due to confusing information from the literature. Li et al. [73] combined melamine cyanurate (MCA) and pristine HNTs to improve the flame retardancy of PA6. The replacement of 2 wt.\% of melamine cyanurate by HNTs did not significantly improved decomposition behavior of materials under air, according to TGA data. Likewise, LOI was improved by only 0.2 from 31.5 for PA6 with 12 wt.\% of MCA to 31.7 for PA6 filled with 10 wt.\% of MCA and 2 wt.\% of HNT. HNTs was also combined at a content of $5 \mathrm{wt} . \%$ with various flame retardants such as antimony trioxide, magnesium hydroxide and melamine cyanurate to retard flame in NBR matrix [74]. Two methods of vulcanization and several contents of flame retardants were also examined, but in most cases formulations free of HNTs were missing for comparison. Therefore, it was not possible to conclude about the synergistic role of HNTs on flame retardancy.

The most obvious synergism was surely observed by combination of HNT and phosphorus flame retardants acting as char promoter that led to the formation of an insulating char layer limiting the heat and mass transfer between the flame and the material. The char can be foamed when flame retardant is intumescent. HNTs as a mineral filler acts for physical reinforcement of char 'aluminosilicate skeleton-frame' [75]. HNT chemically interacts with phosphorus flame retardants to form aluminophosphate products providing the char with a higher thermal stability and better structural properties. Accordingly, the barrier effect of the char gets more efficient. A low amount of HNTs in replacement of an intumescent flame retardant (IFR) allows 
further reduction in pHRR value. For example, the partial replacement of ammonium polyphosphate (APP)-based IFR by only $1.5 \mathrm{wt} \%$ of HNT in a system having total flame retardant loading of $20 \mathrm{wt} \%$ in PP enhanced the UL94 rating from V1 to V0, delayed and reduced the second pHRR in mass loss calorimetry [75]. The authors confirmed that the char was more homogeneous with smaller close-packed cells, and was principally developed faster. Nucleating effect of HNTs on gas bubbles formation was suggested as a mechanistic explanation. This was in confidence with the observation that the temperature at the bottom surface of the sample has increased more slowly and stabilized at a lower temperature. The formation of aluminophosphate compounds was also evidenced by nuclear magnetic resonance (NMR) analyses. Silicoaluminophosphate products formation was also detected with FTIR by Attia et al. [49] in ABS filled with APP-based IFR and HNT, and also with EDX in PBS filled with phosphorus flame retardants and HNT studied by Dumazert et al. [66]. These species (aluminophosphate) were believed to promote the formation of phosphoric acid, dehydration, and crosslinking charring [76].

Zhao et al. [77] have also observed a delay in the thermo-oxidative degradation of the residue from low-density polyethylene (LDPE) filled with IFR when a small amount of HNT was incorporated into the system. They partially replaced IFR by $0.5-3 \mathrm{wt}$.\% of HNT (total flame retardant loading 30 wt.\%) and found that 2 wt.\% of HNT was the most effective loading, for which LOI increased from 29 to 36.5. Moreover, while the residue content in cone calorimetry was ca. 15-20 wt.\% for all other formulations, it reached 60 wt.\% in this case, evidencing that the barrier effect became insulating enough to protect a significant fraction of underlying material. Very similar results were pointed out by Wang et al. [78] when they incorporated HNTs into PBS flame retarded with IFR. Significant increase in LOI was obtained from 42.1 to 58.2 with only 1.5 wt.\% of HNT incorporation. Such content was also corresponding to the best performance measured in cone calorimetry, and efficient barrier effect of the intumescent layer resulted in non-pyrolyzed polymer. As noted by Zhao et al., further addition of HNTs led to deterioration of flame retardancy. The authors suggested that a too high content of HNTs may embrittle the char and favor its degradation under pressure of pyrolytic gases. In both previous articles, synergism was especially highlighted with LOI test: HNT strongly enhanced LOI of 
polymers flame retarded with IFR systems. By contrast, HNT was not able to improve LOI when used alone.

Kaolinite and HNTs were combined to improve the flame retardancy of PP containing IFR [79]. The best ratio was obtained for kaolinite/HNT 9/1 weight ratio, so that $1.5 \mathrm{wt} \%$ of this combination allowed reaching a LOI of 36.9 versus 32.5 and 35.2 for 1.5 wt.\% of kaolinite and HNT alone, respectively. The pHRR decreased from $438 \mathrm{~kW} / \mathrm{m}^{2}$ for PP filled with $25 \mathrm{wt} . \%$ of IFR to 373,341 and $263 \mathrm{~kW} / \mathrm{m}^{2}$, respectively when $1.5 \mathrm{wt}$.\% of kaolinite, HNT and the combination of both replaced a fraction of IFR. Char content was also much higher (+10 wt.\%) for the hybrid system. The authors explained that kaolinite aggregates on the surface of the material during burning, while HNT acts like reinforcing steel bars into concrete. The char was also more resistant under the pressure of gases generated by burning.

Some reports reveal that HNT can also be used to reinforce residues in phosphorus-free formulations. For instance, Anyszka et al. [80] compared different mineral fillers to improve the flame retardancy of styrene-butadiene rubber (SBR) ceramifiable composites. The ceramization was promoted by glassy frit. The content of mineral fillers (HNTs, mica, wollastonite and calcined kaolin) was 145 phr equal to ca. 35 wt.\%. The formulations were vulcanized with sulphur and other constituents, including precipitated silica and zinc oxide. No obvious difference was observed between the four mineral fillers in terms of HRR. The pHRR was significantly decreased in comparison to the reference filler-free formulation containing more polymers. Time-to-ignition (TTI) was also enhanced with mineral fillers, especially HNTs. Compression strength of the composite after ceramization was almost unchanged for HNT, mica and calcined kaolin, but still considerably lower for wollastonite.

In some cases, no or limited improvement was observed when HNT was combined with phosphorus flame retardant. The replacement of $5 \mathrm{wt} . \%$ of IFR by HNT in flame-retarded ABS (FR loading 30 wt.\%) led to a fall of about 53\% in pHRR in comparison to pure ABS [49]. The performance of ABS filled with 30 wt.\% of IFR alone was not reported by the authors, but 30 wt.\% of HNTs alone led to a decrease of $38 \%$. The decrease obtained by combining IFR and HNT as such that the HRR curve shape suggested a quite limited synergism. Vahabi et al. [71] 
compared fire performance of PP/PA6 blends containing 15 wt.\% of APP or aluminum phosphinate (OP1311) with and without 5 wt.\% of HNTs. According to pHRR measured in cone calorimetry, HNT deteriorated the flame retardancy of PP/PA6 filled with APP and did not improve the performance of PP/PA6 filled with OP1311. A similar tendency was detected by Isitman et al. [81] about polylactic acid (PLA) biodegradable polymer flame retarded with aluminum diethylphosphinate and HNT. Dumazert et al. [66] compared the performance of PBS filled with 20 wt.\% of ammonium polyphosphate or aluminum diethylphosphinate with those of PBS containing $15 \mathrm{wt} . \%$ of the same flame retardants and $5 \mathrm{wt} . \%$ of mineral fillers (HNT and sepiolite) by cone calorimetry. Both fillers appeared unsuccessful in reduction of the pHRR.

In some cases, synergism was claimed to exist without any evidence, where a reliable criterion for evaluating synergistic effects between HNTs and a secondary flame retardant was lacking in confidence. However, some attempts to quantify synergism were meritorious. Sun et al. [82] attempted to detect and report the synergism between melamine polyphosphate and HNTs as flame retardants added to PA6. The flame retardant content was fixed to $12 \mathrm{wt} . \%$ to maintain the spinnability of PA6. Formulations were V2-rated and flame retardants slightly improved LOI from 22 to 24, which was in vivid contradiction to the works discussed previously. Thus, it could be speculated that the amount of additive was low for enhancing LOI. Melamine polyphosphate was unable to improve the flame retardancy in cone calorimetry, but addition of raw HNT allowed reaching higher performance. A melamine polyphosphate (MPP)/HNT weight ratio of 5/7 appeared to be the most efficient hybrid system. By comparing the improvements provided by the combination MPP/HNT with those provided by both additives separately, the authors calculated synergistic effectivity (SE) index, so that values higher than 1 evidenced synergism. As an example, combining 5 wt.\% of MPP and 7 wt.\% of HNT corresponded to a SE index of 1.63 on the pHRR measured in pyrolysis-combustion flow calorimetry, that was the decrease in pHRR by $63 \%$ was higher than the sum of the separated effects of MPP and HNT according to a linear rule of mixture. Tang et al. [83] also calculated synergistic index based on LOI measurements and showed a moderate synergism between kaolinite nanoroll and IFR in PP. When the comparison was possible, addition of pristine HNT once again led to less performance than other fillers when combined with phosphorus flame retardants. Isitman et al. [81] 
compared silica, HNTs and OMMT to improve the flame retardancy of PLA filled with aluminum diethylphosphinate. The total flame retardant loading was fixed at $20 \mathrm{wt} . \%$, and the content of nanoparticles in replacement of a fraction of aluminum diethylphosphinate was $3 \mathrm{wt} . \%$. While MMT exerted a great positive effect by reducing the pHRR from 443 to $283 \mathrm{~kW} / \mathrm{m}^{2}$, silica had no significant effect, while HNT even assisted in the flammability. The already cited study of Vahabi et al. [71] shows that OMMT and sepiolite improve the flame retardancy of PP/PA6 filled with phosphorus flame retardants, but not HNT. Gibson observed that HNT improves the insulating character of an intumescent coating, better than CNTs and graphene. The authors attributed this performance to an improvement of the char structure, but it might be, at least partly, due to the high thermal conductivity of carbon-based nanoparticles themselves [84].

\subsection{Reasons why raw HNTs is poorly efficient}

Some explanations can be proposed for the low flame retardancy performance of raw HNT. Dispersion of nanoparticles in polymer matrix is often a key parameter to reach the best fire performance. Homogeneous dispersion of HNT is believed to be relatively easy in polymers and some authors have reported that macromolecules from matrix can penetrate into HNTs lumen on the basis of transmission electron microscopy (TEM) observations $[57,58]$. Such phenomenon would be indicative of acceptable affinity between HNTs and polymers. Nevertheless, in some articles, dispersion of HNT was poor and large aggregates were observed. Moreover, it has been reported that HNT could not appropriately been intercalated by polymer macromolecules, preventing an optimal dispersion. Therefore, HNTs interactions with the matrix should then be limited, especially with non-polar matrices. Improvement of flame retardancy or thermal stability was reported when compatibilization was achieved signifying the role of dispersion on fire retardancy performance.

The efficiency of barrier effect, i.e. the tortuous path formed by nanoparticles, is believed to be dependent on the shape of nanoparticles. Cipiriano et al. [85] have shown that high aspect ratio CNTs in PS significantly decreased mass loss rate than CNTs having low aspect ratio. However, aspect ratio of HNT would be lower than organomodified plate-like MMT or carbon nanotubes. 
Isitman et al. [81] declared that the efficiency of nanoparticles into PLA flame retarded with aluminum diethylphosphinate was associated to their ability to migrate from the bulk to accumulate at the top surface of the material during burning. Such migration would be dependent on the surface free energy of the nanoparticles as well as their size and aspect ratio. The authors did not give any quantity for the surface free energy, but speculated that the migration and accumulation happened slower for HNT due to its lower specific surface area than for silica and MMT, especially when MMT was exfoliated. Nevertheless, no difference in migration or accumulation kinetics was experimentally determined/reported.

The role of particles shape in flame retardancy behavior is complex and it is not always predominant. Based on LOI and cone calorimeter data, tubular halloysite was more efficient than plate-like kaolinite as synergist in PP flame retarded with IFR [79]. The authors assigned this slightly better performance to the higher reactivity of HNT with IFR. The same research team also synthetized kaolinite nanoroll and compared its efficiency as flame retardant with plate-like kaolinite particles [83]. While the nature of HNT was similar to that of kaolinite, nanoroll could be considered as a structure very close to HNT. The authors found that nanoroll was more efficient than plate-like kaolinite as flame retardant additive in the PP matrix filled with IFR. LOI was enhanced more obviously and the pHRR decreased from 438 for nanoparticlefree PP/IFR to $269 \mathrm{~kW} / \mathrm{m}^{2}$ with $1.5 \mathrm{wt}$ \% of nanoroll, against $373 \mathrm{~kW} / \mathrm{m}^{2}$ with $1.5 \mathrm{wt} \%$ of platelike kaolinite. Nanoroll also led to higher char content than plate-like kaolinite. However, neither nanoroll nor plate-like kaolinite improved the UL94 rating or LOI when used alone.

We have already mentioned the influence of viscoelasticity on the flame retardancy. Of course, this parameter is closely linked to the ones discussed above, such as dispersion state and aspect ratio. However, when available, rheological data show that HNTs has only a moderate influence on viscosity $[62,65]$.

Dumazert et al. [86] have calculated the phosphorus fraction remaining in residues from PBS filled with APP or aluminum diethylphosphinate and HNTs. The presence of HNT allowed a fall in the phosphorus content when APP was used. On the contrary, when aluminum diethylphosphinate was used, the phosphorus content was very low, but increased in the 
presence of HNT. In both cases, HNT did not improve the flame retardancy, and then no correlation could be drawn between the fire performance and the phosphorus distribution between gas and condensed phases. Nevertheless, such data might provide new explanations about the relative efficiency of different fillers. For example, the phosphorus content of char from PP/IFR containing kaolinite nanoroll was higher than that of PP/IFR containing plate-like kaolinite, which could explain the better results measured in cone calorimetry with nanoroll [83]. According to Dumazert et al. [86], HNT does not remain stable during burning in cone calorimetry at an irradiance of $50 \mathrm{~kW} / \mathrm{m}^{2}$. The authors studied PBS filled with phosphorus flame retardants and sepiolite or HNT. From X-rays diffraction analysis carried out on residues, the authors observed that sepiolite was stable, but in turn HNT decomposed into quartz. Attention should be paid to the fact that many authors observed the tubular structure of HNT in char from polymers filled with these fillers, evidencing that their structure was not strongly modified during burning. Tubular shape was reported to be preserved up to $900{ }^{\circ} \mathrm{C}$ [87].

\subsection{Halloysite-based hybrid flame retardant systems}

Some authors reported the synthesis of new flame retardants combining HNT and another additive. Zhang et al. [88] developed a flame retardant hybrid combining HNT and graphene oxide and used it to retard flammability of a cyanate ester resin. Firstly, HNT was modified by 3aminopropyltriethoxysilane and then amino groups of modified HNT reacted with epoxy groups on graphene oxide. Dispersion of the hybrid was appropriate, contrarily to the dispersion of both fillers alone. While the additive combination of both fillers in 2 wt.\% of graphene oxide and $2.5 \mathrm{wt}$.\% of HNT did not provide significant improvement of the fire properties of the resin, the incorporation of $5 \mathrm{wt} . \%$ of the hybrid led to better fire performance. The authors concluded that the hybrid promotes a denser char with a high graphitization degree, quite often related to a better thermal stability, leading to a better barrier effect.

Dong et al. [89] synthetized a hybrid based on HNT and ferrum ammonium phosphate (FAP). This flame retardant (FAP-HNT) contained high amounts of phosphorus (4.73 atom \%), nitrogen (9.27\%) and iron (6.38\%). This hybrid allowed decreasing the HRR measured in pyrolysis 
combustion flow calorimetry (PCFC), but V2 rating in UL94 was obtained only for a content of 20 wt.\%. Based on UL94 test, the combination with aluminum phosphinate did not seem to provide a significant synergism.

\section{Different routes of modification of HNTs}

There are many articles dealing with the modification of HNTs, and especially recent articles and reviews [90-96]. The objective of the next paragraph is not to list all the contributions made to the knowledge, in turn it is aimed to summarize different ways of modification and to focus on the modifications dedicated to thermal stability and fire reaction improvement. In the literature, authors have developed a wide range of strategies to chemically modify HNTs. Procedures of coating, physical or chemical grafting with molecules, macromolecules or nanoparticles, chemical loading or intercalation and corrosive process were more or less used. Surface modification of HNT can be obtained by direct treatment agents in solution to obtain a layer at the nanoparticle surface. Moreover, the formation of this layer can also be obtained by reactive strategies based on silane condensation [97] or in situ polymerization [98] in presence of HNT.

Grafting of HNTs based on physical interactions was also proposed. For non-covalent modifications, strong physical interactions with HNT surface are needed and molecules which can form physical bonds with surface functions like hydroxyls are generally acceptable. Various chemical products are also reported for these procedures which are aided by chelating ligands $[99,100]$, ionic liquids [101], carbohydrates [102] or surfactants [103,104].

For covalent functionalization, the diversity of the procedures developed so far is reported. Some authors have grafted molecules and macromolecules in the presence of hydroxyl groups at the clay surface (silanols and aluminol). The formation of the covalent bond between the organic part and the clay surface was made with treatment agent bearing alkoxysilane, phosphonic acid, catechol or boronic acid functional groups. The condensation reactions of these functions with hydroxylated HNT form covalent bonds between the grafting agents and the clay. In the literature, authors have developed simple strategies based on one-step 
procedure, but also more complex ones based on multistep procedures where the grafting agents bearing reactive functions amine [105-108], epoxide [109], alkyl halide [110,111], thiol [112] allow the introduction of new groups at HNT surface. As an example, the grafting of HNT with macromolecules could be done with a "grafting onto" one-step procedure or with a "grafting from" or "grafting through" multistep procedure. For "grafting onto" procedures [113], macromolecular grafting agents bearing functions reactive with halloysite hydroxyl groups are used. Whereas in "grafting from" [114, 115] (or "grafting through" [116]) procedures, the first step is devoted to the functionalization of halloysite with an initiator (or a reactive group), which can be then used in a next step for a polymerization reaction. More complex procedures in which HNT is directly decorated by hyperbranched polymers or through two-step procedures with silica nanoparticles and then hyperbranched polymers are also reported.

Multistep procedures were also used for anisotropic functionalization of HNTs due to its tubular structure with aluminol groups at the inner surface and silanol at the outer. This asymmetry of composition led to large differences in the reactivity of pristine and surface-functionalized nanoparticles, which allowed selective modification. Phosphonic acid, catechol or boronic acid functional groups are reactive only with aluminol groups, whereas alkoxysilanes functions are reactive with both silanol and aluminol groups. Such a contradictory behavior made possible to modify the inner surface selectively in the first step before the modification of the outer surface of the clay.

In many studies, HNTs was used as support for metal or metal oxide nanoparticles. Iron $[117,118]$, copper [119,120], cobalt [119], silver [121], gold [122], titanium [123] or palladium [124] were examined in this regard. The metal or metal oxide nanoparticles were generally formed in situ and deposed directly on the lumen surface or complexed using grafted chelating ligands.

HNT can also be used as carrier system to entrap molecules in different ways including adsorption to the external and internal walls of the tubes [125], intercalation [126] and loading of the substances into the lumen [127]. Its empty 15-30 nm diameter lumen makes it an 
efficient container for the loading for the time-dependent release of chemical agents [87]. The inner lumen of HNT can be adjusted by etching to $20-30 \%$ of the tube volume [128] and loaded with functional agents like antioxidants, anticorrosion agents, flame-retardant agents, drugs, or proteins. This characteristic attracted much attention toward HNT in the pharmaceutical field due to the possibility to obtain controlled-release drug-delivery systems combined with its unique characteristics as non-toxicity and biocompatibility [129]. Release of chemical agents from HNT usually takes place in two stages: fast release of agents physisorbed on the nanotube ends and the external surface followed by the slow release from the inner lumen.

\subsection{Outer surface modification of halloysite to improve compatibility with matrix}

As mentioned previously, the structure of halloysite nanotubes allows both outer modification of silanol groups and inner modification within the lumen by either encapsulation (loading) or grafting onto aluminol groups. The following paragraph concerns with the first way of modification in which the outer modification of silanol groups is performed. In particular, the influence of outer modification on fire properties of the polymer was the reason for such treatments. As already reported, the presence of HNT can improve or, in turn, decrease the thermal stability of the host polymer. Szpilska et al. [47] reviewed the role of HNT in polyolefins. The authors explained that HNT tends to decrease the thermal stability due to the decomposition of hydroxyl groups on the surface of HNT (which was the case for many other types of clay) which act as Brönsted sites catalyzing the degradation of polyolefins. The shielding of acidic groups on HNT by surface modification as well as the improvement of interactions between polymer and HNT by the use of compatibilizing agent can enhance the thermal stability as well. Du et al. [63] compared raw and silane-modified HNT in PP matrix. The thermal stability of PP was enhanced with raw HNT, but much more with the silane-modified HNT. Temperature at $5 \mathrm{wt}$ \% of mass loss under nitrogen flow was increased accordingly from 384 to $414{ }^{\circ} \mathrm{C}$ with 10 wt.\% of raw HNT, but reached $444{ }^{\circ} \mathrm{C}$ with modified HNT. An improvement of thermal stability under air was also observed, but less significantly compared to inert atmosphere. Such phenomenon was observed occasionally in other polymers. As an 
example, Arat and Uyanik [68] compared the thermal stability of polystyrene (PS) filled with raw HNT and also HNT modified with styrene-maleic anhydride copolymers using TGA measurements under nitrogen. While raw HNT decreased the thermal stability of PS (temperature at $10 \mathrm{wt} . \%$ of mass loss, $\mathrm{T}_{10 \%}$ dropped from 387 to $340{ }^{\circ} \mathrm{C}$ with $15 \mathrm{wt} . \%$ of filler), the modified HNT allowed a limited increase with $\mathrm{T}_{10 \%}$ slightly higher than $400{ }^{\circ} \mathrm{C}$. Note that the content of surface modifier was not reported in that study.

Lecouvet et al. $[62,64,75,130]$ have obtained some interesting results using a water-assisted extrusion process to prepare HNT nanocomposites. The process consisted of injecting water during extrusion. At high pressure and temperature, water remained in the form liquid and miscibility with polymer could be achieved. A fraction of water was in excess and did not participate to polymer dissolution. Water was removed at the end by vacuum pump. This process allowed improving the dispersion of HNTs through several mechanisms. Water could promote the ionization of silanol groups at the surface of HNT, reinforcing the affinity between the particles and the polymer. Moreover, water in excess might lead to aqueous suspension of HNT and shear forces during extrusion could disaggregate them more easily.

Polyethersulfone (PES)/HNT nanocomposites were prepared by Lecouvet et al. in another study [62]. The best dispersion was achieved when water injection efficiency was combined with a PES bearing $-\mathrm{OH}$ groups at chain ends rather than $-\mathrm{Cl}$ groups. The authors proved that condensation reaction occurred between phenol groups of PES and silanol groups of HNTs. Thermal stability was enhanced as featured by a significant increase in TTI measured by mass loss calorimetry. The pHRR was strongly decreased (see Figure 4.4), and HNT addition improves the mechanical resistance of the intumescent char layer developed from PES decomposition, leading to a non-pyrolyzed fraction of polymer. The thermo-oxidative degradation of the char at the end of the test after flame out was also slowed down. Nevertheless, no comparison was made with composites prepared without water injection. In another work, the same authors prepared PP composites filled with HNTs [64]. Once again, water injection improved the dispersion and the best dispersion was obtained combining water injection and the incorporation of polypropylene-grafted-maleic anhydride (PP-g-MAH) as compatibilizer. The authors did not observe any evidence of interactions between HNT and PP-g-MAH, but they 
speculated that water promotes interactions between carboxylic diacid functions of PP- $g$-MAH, and also declared that HNT surface led to a good dispersion during high compression zone in the extruder. After water degassing, hydrogen bonds were probably removed due to the (re)formation of anhydride functions of PP-g-MAH. Anyhow, the decrease in pHRR observed through mass loss calorimetry was much impressive for composites prepared with PP-g-MAH and water injection (Figure 4.4). The process was also carried out to prepare PA12/HNT nanocomposites. In spite of a better dispersion of HNT nanoparticles in PA12, water injection did not significantly improve the fire performance measured by mass loss calorimetry [130].

\subsection{Loading flame retardant into halloysite lumen}

The following part concerns the second way of functionalization. That is loading or grafting into the lumen. This strategy benefits from the main specification of HNT that is the ability of using large lumen galleries to load additives inside. This approach has been tested in many applications, especially in drug release and photocatalysis fields [87,131]. The relatively large 15 $\mathrm{nm}$ diameter of lumen makes it possible to entrap small molecules inside the lumen, considering that the lumen provides the molecules with a volume of around 10 vol.\%. Moreover, etching the HNTs by dissolution of aluminum oxide allows increasing the lumen diameter and volume up to $21 \mathrm{~nm}$ and 30 vol.\%, respectively, without modifying the tube outer diameter (50 nm) [87]. As mentioned previously, selective modification can be reached because the inner and outer surface chemical nature being different. As an example, Yah et al. [132] selectively bounded phosphonic acid to alumina sites in halloysite lumen, where no intercalation into interlayer was observed. Subsequent silanization of the outer surface evidenced the selective bi-functionalization of HNT.

Some authors also attempted to incorporate a flame retardant or a component of a complex flame retardant system into HNT lumen. Note that such encapsulation can be motivated by other objectives than fire performances: avoiding migration of flame retardant additive, reducing the negative impact of flame retardant on moisture absorption [60] or mechanical properties (plasticizing effect of flame retardant) [76]. 
Marney et al. [133] functionalized HNT by exchange of its hydroxyl sites with phenylphosphonic acid (PPA). From X-ray diffraction (XRD) spectroscopy analysis the authors confirmed that PPA is present in the interlamellar spaces, but it is also probably expected into the lumen. From TGA under air, a rapid calculation allowed to assess the content of PPA in HNT: 28 wt.\%, i.e. around 5.5 wt.\% of phosphorus. The incorporation of 5 or 10 wt.\% of raw HNT into PA6 decreased the pHRR measured in cone calorimeter, but the curve still showed an intense peak after a plateau, characteristic of vigorous burning. In agreement with this observation, LOI was only slightly enhanced from 23.0 to 24.6 with 10 wt.\% of halloysite. Addition of 5 wt.\% of PPA modified HNT to the polymer increased the pHRR. By contrast, the HRR curve was strongly changed with 10 wt.\% of PPA-modified HNT. The pHRR after the plateau vanished; evidencing that burning has been controlled. According to the authors, this was assigned to a change in the porous structure of the char, while the char content (which could reveal the char promotion effect of PPA) was not given. Nevertheless, LOI was reduced from 21 for 10 wt.\% of PPA-modified HNT.

Using almost the same protocol as Marney et al. [133], Sahnoune et al. [134] grafted methyl phosphonic acid (MPA) onto the aluminol groups of HNT from an Algerian deposit. XRD proved that there was no change in the crystalline structure of the nanotubes. Moreover, 2 wt.\% of phosphorus was grafted onto HNT, as measured by inductively coupled plasma atomic emission spectroscopy (ICP-AES). The PA11 formulations containing 20 wt.\% of raw (H) or MPA-modified HNT (HP) were compared with PA11 formulations containing 20 wt.\% of APP or a mixture of APP and HNT. The incorporation of HP into the PA11 clearly enhanced the thermal stability and reduced pHRR in PCFC, especially under anaerobic pyrolysis. This had a huge impact on cone calorimeter results. Especially, a higher TTI for formulations comprising HP and particularly $\mathrm{H}$ was obvious compared to the formulations containing APP. Moreover, a thick charring effect detected by a fall of $57 \%$ of pHRR compared to pure PA11 was reported for the PA11/20HP system. It was assumed that MPA grafted on the HNT lumen reacted with PA11 during burning and formed a cohesive residue.

Li et al. [135] modified HNT with maleic anhydride and then with 9,10-dihydro-9-oxa-10phosphaphenanthrene-10-oxide (DOPO). The content of DOPO in the modified HNT was estimated to be equal to 16 wt.\%. This led to a 2.3 wt.\% of phosphorus in the modified HNT 
structure. DOPO was grafted both on outer and inner surfaces of maleic anhydride modified HNTs. Limited intercalation and the presence of crystalline DOPO in lumen were also proposed. The DOPO-modified HNT was incorporated into PLA. The main mode-of-action of DOPO is flame inhibition, not char promotion. Therefore, charring was not obviously enhanced according to cone calorimeter data. On the contrary, LOI was strongly enhanced with 5 wt.\% of DOPOmodified HNT, which was ca. 0.8 wt.\% of DOPO. The value of 38 versus $24.7,28.2$ and 30.8 for pure PLA, PLA filled with 5 wt.\% of raw HNT and PLA filled with HNT and DOPO in total amount 5 wt.\%, was respectively noticeable. V0 rating was also obtained in UL94 test, where slow release of $\mathrm{PO}^{\circ}$ radicals during burning was believed to explain such interesting result.

Zheng and $\mathrm{Ni}$ [76] loaded dimethyl methylphosphonate into HNT lumen by applying a vacuum procedure. The loading content was $\mathbf{2 4 . 2}$ wt.\% leading to a phosphorus content in the HNT of about 6 wt.\%. The authors considered that a fraction of the flame retardant was also adsorbed on HNT surface. Incorporation of 20 wt.\% of modified HNT improved significantly the fire performance of UV-cured epoxy resin measured in cone calorimetry. The pHRR drastically decreased from $1002 \mathrm{~kW} / \mathrm{m}^{2}$ for pure epoxy to $578 \mathrm{~kW} / \mathrm{m}^{2}$ when adding $20 \mathrm{wt}$ \% of modified HNT, versus $790 \mathrm{~kW} / \mathrm{m}^{2}$ with $20 \mathrm{wt} . \%$ of raw HNTs. The residue content was the same in both cases (20 wt.\%), but the residue was much thinner with pristine HNT. The same team has also loaded HNT with pentaerythritol (PER) by vacuum suction followed by only one washing step by distilled water to prepare flame retarded epoxy composites with reduced moisture absorption [60]. The content of PER into HNT was as high as 41.7 wt.\%, and the authors concluded that PER was probably not only in the lumen but also absorbed in the external cavities or on the surface of the HNT. Modified HNT improved LOI of epoxy alone slightly better than raw HNT, but the enhancement was very limited (20.8 with 20 wt.\% of modified HNT versus 18 for the pure epoxy). It should be mentioned that PER is not inherently flame retardant, but typically the presence of carbon source in the intumescent flame retardant system could be of worth. Combination of the modified HNT with APP in the epoxy resin assist in formation of an intumescent char, suggesting that reaction took place between the APP and PER. The authors also showed that the reaction between APP and PER was catalyzed in the presence of HNT, particularly at low temperature. The pHRR was correspondingly declined from 1002 to 562 
$\mathrm{kW} / \mathrm{m}^{2}$ upon addition of $10 \mathrm{wt} . \%$ of modified HNT in combination with $15 \mathrm{wt} . \%$ APP to the epoxy. The total heat release (THR) was also strongly reduced, evidencing that the char protects the underlying material from pyrolysis. Unfortunately, some formulations containing only one component (modified HNT or APP) were not tested to assess synergism between additives.

Jing et al. [136] firstly hydrophobized HNT lumen with octadecylphosphonic acid and then loaded it with bisphenol-A bis(diphenylphosphate) (BDP), a common flame retardant. Thanks to the hydrophobization, the loading of BDP into the modified HNT was strongly enhanced in comparison to raw HNT. The controlled release of BDP in tetrahydrofuran (THF) was also investigated. Nevertheless, even if it was not shown in the report, the release kinetics in such a highly viscous matrix was expected to be very different. In fact, two phenomena could be considered. The first phenomenon was the release from polymer at room temperature during service life, where slow release would be beneficial to avoid migration and blooming of the flame retardant. The second was the release during burning, when the polymer matrix becomes less viscous at high temperatures. For that purpose, a convenient method was to assess the temperature at which the flame retardant would release. The effect and control of release kinetics of the flame retardant on the fire performances is a very interesting topic, which has not been addressed yet. To the best of our knowledge, only Li et al. [135] have provided first insights into such a phenomenon. They ascribed higher fire performance obtained for PLA filled with HNT, which itself was loaded with DOPO (in comparison to PLA filled with the same

amount of pristine HNT and DOPO separately) to the continuous release of DOPO during burning. Indeed, the authors observed several new mass loss steps in TGA for HNT modified with DOPO. These steps were assigned to DOPO release, which itself depends on the DOPO state (free ungrafted or grafted DOPO) or its location on HNT.

\section{Concluding remarks and future perspective}

The physical, chemical, and mechanical properties of clays together with their abundance in the nature make them a promising candidate for many uses. Typically, platelet-like (platy) and tubular forms of clay are frequently considered by the researchers and engineers alike to 
improve thermal stability and flame retardancy of polymers. In general, it has been accepted that, depending on intercalation and exfoliation state, thermal and fire properties of polymers filled with platy nanoclays may vary, but as a consequence of hydrophilic nature of clays and their inherent incompatibility with polymer matrices proper dispersion of platelet-shape clay minerals in polymers has remained as an open challenge. Incorporation of a given kind of nanoclay into polymers leads to various sorts of thermal behavior depending on physical and chemical interaction between polymer chains and additives. Platy nanoclays quite often play the role of thermal barrier against thermal degradation, but they may function as a thermal decomposition facilitator via heat accumulation caused by stacking silicate layers or catalytic effect of hydroxyl groups that accelerate decomposition of polymer chains. HNTs are another form of clay mineral consisting of rolls of same chemical composition than kaolinite with an outer silica tetrahedral surface layer and an inner alumina octahedral surface. Interestingly, various modes-of-action were observed in addition to well-accepted barrier effect by HNT accumulation. However, research of their effect on thermal stability and flame retardancy behavior is subjected to some contradictory observations similar to platy clay. Lumen of HNT is believed to trap volatiles during burning. Many authors have evoked this assumption, firstly proposed by $\mathrm{Du}$ et al. [63]. Some others also proposed several possible modes-of-action, including the entrapment of radicals or volatiles into lumen. Nevertheless, as noticed by Lecouvet et al. [130], there is no evidence of such mechanism, as Du et al. [63] do not claimed for its approval. Wang and Huang [61] reported higher thermal stability for PP filled with HNT, but not arising from radicals.

The presence of iron impurities has also been proposed as a potential flame retardant mechanism. Indeed, iron can catalyze decomposition and scavenge radicals. According to the HNT origin, its $\mathrm{Fe}_{2} \mathrm{O}_{3}$ content is few tenth of a percent. Nevertheless, this assumption has not been evidenced up to now. The accumulation of mineral filler on the top surface of a material during burning is primarily due to the ablation of the polymer. Nevertheless, in the case of nano-scale or sub-micron fillers, migration has also been reported, accelerating the enrichment of the surface in the inert fillers $[137,138]$. Such phenomenon allows organo-mineral layer acting faster as protective insulating layer. Migration of HNT was not excluded and some 
authors have suggested it, but no evidence has been reported yet. Two other potential mechanisms can also be considered: the water release from HNT allowing the dilution of fuels in gas phase and the corresponding cooling effect due to the endothermic nature of this decomposition. The de-hydroxylation of HNT between 450 and $550{ }^{\circ} \mathrm{C}$ featured by releases 10 wt.\% of water and absorbing $620 \mathrm{~kJ} / \mathrm{kg}$ of energy was also considered as some evidences [130]. Nevertheless, such release occurs at relatively high temperatures, where the absorbing energy is quite low in comparison to other metal hydroxide products, and the HNT content is generally low to moderate. Therefore, these effects are believed to be minor or negligible. All in all, it can be concluded that HNT or clay are not alone responsible for high thermal stability and/or flame retardancy, even if they are surface modified. On the other hand, when a combination of one of them with other flame retardant additives or hybrid systems are used, still mechanistic explanations are fuzzy, and need to be supported by sufficient evidence. Therefore, future ahead of this field necessitates evaluation of synergism between nanoclay and other flame retardants, both theoretically and experimentally.

\section{References}

[1] A. Usuki, N. Hasegawa, M. Kato, S. Kobayashi, Polymer-clay nanocomposites, in: Inorganic polymeric nanocomposites and membranes, Springer, 2005, pp. 135-195.

[2] A.E. Jahromi, A. Arefazar, O.M. Jazani, M.G. Sari, M.R. Saeb, M. Salehi, Taguchi-based analysis of polyamide 6/acrylonitrile-butadiene rubber/nanoclay nanocomposites: The role of processing variables, Journal of Applied Polymer Science, 130 (2013) 820-828.

[3] T.S. Kermaniyan, H. Garmabi, M.R. Saeb, Calorimetric and rheokinetic analyses merged to capture crystallization kinetics in polyamide/clay nanocomposites: Revisiting predictability of models, Journal of Applied Polymer Science, 135 (2018) 46364.

[4] P. Kiliaris, C. Papaspyrides, Polymer/layered silicate (clay) nanocomposites: an overview of flame retardancy, Progress in Polymer Science, 35 (2010) 902-958.

[5] S.M.R. Paran, M.R. Saeb, K. Formela, V. Goodarzi, P. Vijayan P, D. Puglia, H.A. Khonakdar, S. Thomas, To what extent can hyperelastic models make sense the effect of clay surface treatment on the mechanical properties of elastomeric nanocomposites?, Macromolecular Materials and Engineering, 302 (2017) 1700036. 
[6] A.E. Jahromi, H.R.E. Jahromi, F. Hemmati, M.R. Saeb, V. Goodarzi, K. Formela, Morphology and mechanical properties of polyamide/clay nanocomposites toughened with NBR/NBR-g-GMA: a comparative study, Composites Part B: Engineering, 90 (2016) 478-484.

[7] H.H. Murray, Structure and composition of the clay minerals and their physical and chemical properties, Developments in clay science, 2 (2006) 7-31.

[8] L. Deng, P. Yuan, D. Liu, F. Annabi-Bergaya, J. Zhou, F. Chen, Z. Liu, Effects of microstructure of clay minerals, montmorillonite, kaolinite and halloysite, on their benzene adsorption behaviors, Applied Clay Science, 143 (2017) 184-191.

[9] T.J. Pinnavaia, Intercalated clay catalysts, Science, 220 (1983) 365-371.

[10] S. Pavlidou, C. Papaspyrides, A review on polymer-layered silicate nanocomposites, Progress in polymer science, 33 (2008) 1119-1198.

[11] Z. Karami, O.M. Jazani, A.H. Navarchian, M.R. Saeb, State of cure in silicone/clay nanocomposite coatings: The puzzle and the solution, Progress in Organic Coatings, 125 (2018) 222-233.

[12] C.-W. Chiu, T.-K. Huang, Y.-C. Wang, B.G. Alamani, J.-J. Lin, Intercalation strategies in clay/polymer hybrids, Progress in Polymer Science, 39 (2014) 443-485.

[13] M. Kotal, A.K. Bhowmick, Polymer nanocomposites from modified clays: Recent advances and challenges, Progress in Polymer Science, 51 (2015) 127-187.

[14] L. Avérous, E. Pollet, Biodegradable polymers, in: Environmental silicate nano-biocomposites, Springer, 2012, pp. 13-39.

[15] J.M. Cervantes-Uc, J.V. Cauich-Rodríguez, H. Vázquez-Torres, L.F. Garfias-Mesías, D.R. Paul, Thermal degradation of commercially available organoclays studied by TGA-FTIR, Thermochimica Acta, 457 (2007) 92-102.

[16] C.F. Ou, Crystallization behavior and thermal stability of poly (trimethylene terephthalate)/clay nanocomposites, Journal of Polymer Science Part B: Polymer Physics, 41 (2003) 2902-2910.

[17] J.U. Calderon, B. Lennox, M.R. Kamal, Thermally stable phosphonium-montmorillonite organoclays, Applied Clay Science, 40 (2008) 90-98.

[18] W. Xie, Z. Gao, W.-P. Pan, D. Hunter, A. Singh, R. Vaia, Thermal degradation chemistry of alkyl quaternary ammonium montmorillonite, Chemistry of Materials, 13 (2001) 2979-2990.

[19] A. Leszczyńska, J. Njuguna, K. Pielichowski, J. Banerjee, Polymer/montmorillonite nanocomposites with improved thermal properties: Part I. Factors influencing thermal stability and mechanisms of thermal stability improvement, Thermochimica acta, 453 (2007) 75-96.

[20] D. Dharaiya, S.C. Jana, Thermal decomposition of alkyl ammonium ions and its effects on surface polarity of organically treated nanoclay, Polymer, 46 (2005) 10139-10147.

[21] L.B. Fitaroni, J.A. de Lima, S.A. Cruz, W.R. Waldman, Thermal stability of polypropylenemontmorillonite clay nanocomposites: limitation of the thermogravimetric analysis, Polymer Degradation and Stability, 111 (2015) 102-108.

[22] A. Luyt, V. Geethamma, Effect of oxidized paraffin wax on the thermal and mechanical properties of linear low-density polyethylene-layered silicate nanocomposites, Polymer Testing, 26 (2007) 461-470.

[23] M. Zanetti, S. Lomakin, G. Camino, Polymer layered silicate nanocomposites, Macromolecular Materials and Engineering, 279 (2000) 1-9. 
[24] S.S. Ray, M. Okamoto, Polymer/layered silicate nanocomposites: a review from preparation to processing, Progress in polymer science, 28 (2003) 1539-1641.

[25] K. Chrissafis, D. Bikiaris, Can nanoparticles really enhance thermal stability of polymers? Part I: an overview on thermal decomposition of addition polymers, Thermochimica Acta, 523 (2011) 1-24.

[26] D. Bikiaris, Can nanoparticles really enhance thermal stability of polymers? Part II: an overview on thermal decomposition of polycondensation polymers, Thermochimica Acta, 523 (2011) 25-45.

[27] T. Fornes, P. Yoon, D. Paul, Polymer matrix degradation and color formation in melt processed nylon 6/clay nanocomposites, Polymer, 44 (2003) 7545-7556.

[28] S.-L. Bee, M. Abdullah, S.-T. Bee, L.T. Sin, A. Rahmat, Polymer Nanocomposites based on SilylatedMontmorillonite: A Review, Progress in Polymer Science, (2018).

[29] M. Albdiry, B. Yousif, Role of silanized halloysite nanotubes on structural, mechanical properties and fracture toughness of thermoset nanocomposites, Materials \& Design, 57 (2014) 279-288.

[30] R. Kamble, M. Ghag, S. Gaikawad, B.K. Panda, Halloysite Nanotubes and Applications: A Review, Journal of Advanced Scientific Research, 3 (2012).

[31] R. Polanský, P. Kadlec, Z. Kolská, V. Švorčík, Influence of dehydration on the dielectric and structural properties of organically modified montmorillonite and halloysite nanotubes, Applied Clay Science, 147 (2017) 19-27.

[32] P. Yuan, D. Tan, F. Annabi-Bergaya, Properties and applications of halloysite nanotubes: recent research advances and future prospects, Applied Clay Science, 112 (2015) 75-93.

[33] M. Liu, Z. Jia, D. Jia, C. Zhou, Recent advance in research on halloysite nanotubes-polymer nanocomposite, Progress in polymer science, 39 (2014) 1498-1525.

[34] D. Rawtani, Y. Agrawal, Multifarious applications of halloysite nanotubes: a review, Rev. Adv. Mater. Sci, 30 (2012) 282-295.

[35] Y. Zhang, A. Tang, H. Yang, J. Ouyang, Applications and interfaces of halloysite nanocomposites, Applied Clay Science, 119 (2016) 8-17.

[36] H. Vahabi, M. Jouyandeh, M. Cochez, R. Khalili, C. Vagner, M. Ferriol, E. Movahedifar, B. Ramezanzadeh, M. Rostami, Z. Ranjbar, Short-lasting fire in partially and completely cured epoxy coatings containing expandable graphite and halloysite nanotube additives, Progress in Organic Coatings, 123 (2018) 160-167.

[37] H. Vahabi, M.R. Saeb, K. Formela, J.-M.L. Cuesta, Flame retardant epoxy/halloysite nanotubes nanocomposite coatings: Exploring low-concentration threshold for flammability compared to expandable graphite as superior fire retardant, Progress in Organic Coatings, 119 (2018) 8-14.

[38] G. Cavallaro, G. Lazzara, S. Milioto, Dispersions of nanoclays of different shapes into aqueous and solid biopolymeric matrices. Extended physicochemical study, Langmuir, 27 (2010) 1158-1167.

[39] D. Marney, L. Russell, D. Wu, T. Nguyen, D. Cramm, N. Rigopoulos, N. Wright, M. Greaves, The suitability of halloysite nanotubes as a fire retardant for nylon 6, Polymer degradation and stability, 93 (2008) 1971-1978.

[40] N.-y. Ning, Q.-j. Yin, F. Luo, Q. Zhang, R. Du, Q. Fu, Crystallization behavior and mechanical properties of polypropylene/halloysite composites, Polymer, 48 (2007) 7374-7384. 
[41] M. Du, B. Guo, D. Jia, Thermal stability and flame retardant effects of halloysite nanotubes on poly(propylene), European Polymer Journal, 42 (2006) 1362-1369.

[42] B. Wang, H.-X. Huang, Effects of halloysite nanotube orientation on crystallization and thermal stability of polypropylene nanocomposites, Polymer degradation and stability, 98 (2013) 1601-1608.

[43] B. Lecouvet, J. Gutierrez, M. Sclavons, C. Bailly, Structure-property relationships in polyamide 12/halloysite nanotube nanocomposites, Polymer Degradation and Stability, 96 (2011) 226-235.

[44] M. Liu, B. Guo, M. Du, Y. Lei, D. Jia, Natural inorganic nanotubes reinforced epoxy resin nanocomposites, Journal of Polymer Research, 15 (2008) 205-212.

[45] W.J. Choi, S.H. Kim, Y.J. Kim, S.C. Kim, Synthesis of chain-extended organifier and properties of polyurethane/clay nanocomposites, Polymer, 45 (2004) 6045-6057.

[46] E.S. Goda, K.R. Yoon, S.H. El-sayed, S.E.J.T.A. Hong, Halloysite Nanotubes as Smart Flame retardants: A review, (2018).

[47] K. Szpilska, K. Czaja, S.J.P. Kudła, Thermal stability and flammability of polyolefin/halloysite nanotubes composites, 60 (2015).

[48] R.J. Smith, K.M. Holder, S. Ruiz, W. Hahn, Y. Song, Y.M. Lvov, J.C.J.A.F.M. Grunlan, Environmentally benign halloysite nanotube multilayer assembly significantly reduces polyurethane flammability, 28 (2018) 1703289.

[49] N.F. Attia, M.A. Hassan, M.A. Nour, K.E.J.P.I. Geckeler, Flame-retardant materials: synergistic effect of halloysite nanotubes on the flammability properties of acrylonitrile-butadiene-styrene composites, 63 (2014) 1168-1173.

[50] D. Marney, L. Russell, D. Wu, T. Nguyen, D. Cramm, N. Rigopoulos, N. Wright, M.J.P.d. Greaves, stability, The suitability of halloysite nanotubes as a fire retardant for nylon 6, 93 (2008) 1971-1978.

[51] L. Ferry, R. Sonnier, J.-M. Lopez-Cuesta, S. Petigny, C.J.J.o.T.A. Bert, Calorimetry, Thermal degradation and flammability of polyamide 11 filled with nanoboehmite, 129 (2017) 1029-1037.

[52] M. Batistella, B. Otazaghine, R. Sonnier, A.-S. Caro-Bretelle, C. Petter, J.-M.J.P.D. Lopez-Cuesta, Stability, Fire retardancy of ethylene vinyl acetate/ultrafine kaolinite composites, 100 (2014) 54-62.

[53] S. Bourbigot, S. Duquesne, C. Jama, Polymer nanocomposites: how to reach low flammability?, in: Macromolecular Symposia, Wiley Online Library, 2006, pp. 180-190.

[54] T. Kashiwagi, E. Grulke, J. Hilding, K. Groth, R. Harris, K. Butler, J. Shields, S. Kharchenko, J.J.P. Douglas, Thermal and flammability properties of polypropylene/carbon nanotube nanocomposites, 45 (2004) 4227-4239.

[55] T. Kashiwagi, M. Mu, K. Winey, B. Cipriano, S. Raghavan, S. Pack, M. Rafailovich, Y. Yang, E. Grulke, J.J.P. Shields, Relation between the viscoelastic and flammability properties of polymer nanocomposites, 49 (2008) 4358-4368.

[56] J. Courtat, F. Melis, J.-M. Taulemesse, V. Bounor-Legare, R. Sonnier, L. Ferry, P.J.P.D. Cassagnau, Stability, Effect of phosphorous-modified silica on the flame retardancy of polypropylene based nanocomposites, 119 (2015) 260-274.

[57] I.M. Inuwa, N. Che Abdul Razak, R. Arjmandi, A.J.P.C. Hassan, Effects of halloysite nanotubes on the mechanical, thermal, and flammability properties of PP-g-MAH compatibilized polyethylene terephthalate/polypropylene nanocomposites, 39 (2018) E1554-E1564. 
[58] H. Ismail, P. Pasbakhsh, M.A. Fauzi, A.A.J.P.T. Bakar, Morphological, thermal and tensile properties of halloysite nanotubes filled ethylene propylene diene monomer (EPDM) nanocomposites, 27 (2008) 841-850.

[59] G. George, M. Selvakumar, A. Mahendran, S.J.J.o.T.C.M. Anandhan, Structure-property relationship of halloysite nanotubes/ethylene-vinyl acetate-carbon monoxide terpolymer nanocomposites, 30 (2017) 121-140.

[60] T. Zheng, X.J.J.o.A.P.S. Ni, Loading the polyol carbonization agent into clay nanotubes for the preparation of environmentally stable UV-cured epoxy materials, 134 (2017) 45045.

[61] B. Wang, H.-X.J.P.d. Huang, stability, Effects of halloysite nanotube orientation on crystallization and thermal stability of polypropylene nanocomposites, 98 (2013) 1601-1608.

[62] B. Lecouvet, M. Sclavons, S. Bourbigot, C.J.P.d. Bailly, stability, Thermal and flammability properties of polyethersulfone/halloysite nanocomposites prepared by melt compounding, 98 (2013) 1993-2004.

[63] M. Du, B. Guo, D.J.E.P.J. Jia, Thermal stability and flame retardant effects of halloysite nanotubes on poly (propylene), 42 (2006) 1362-1369.

[64] B. Lecouvet, M. Sclavons, S. Bourbigot, J. Devaux, C.J.P. Bailly, Water-assisted extrusion as a novel processing route to prepare polypropylene/halloysite nanotube nanocomposites: structure and properties, 52 (2011) 4284-4295.

[65] B. Lecouvet, J. Gutierrez, M. Sclavons, C.J.P.D. Bailly, Stability, Structure-property relationships in polyamide 12/halloysite nanotube nanocomposites, 96 (2011) 226-235.

[66] L. Dumazert, D. Rasselet, B. Pang, B. Gallard, S. Kennouche, J.M.J.P.f.A.T. Lopez-Cuesta, Thermal stability and fire reaction of poly (butylene succinate) nanocomposites using natural clays and FR additives, 29 (2018) 69-83.

[67] G. Gorrasi, V. Senatore, G. Vigliotta, S. Belviso, R.J.E.P.J. Pucciariello, PET-halloysite nanotubes composites for packaging application: preparation, characterization and analysis of physical properties, 61 (2014) 145-156.

[68] R. Arat, N.J.M.T.C. Uyanık, Study of the morphological and thermal properties of polystyrene nanocomposites based on modified halloysite nanotubes with styrene-maleic anhydride copolymers, 13 (2017) 255-262.

[69] R. Nakamura, A. Netravali, A. Morgan, M. Nyden, J.J.F. Gilman, Materials, Effect of halloysite nanotubes on mechanical properties and flammability of soy protein based green composites, 37 (2013) 75-90.

[70] H. Vahabi, M.R. Saeb, K. Formela, J.-M.L. Cuesta, Flame retardant epoxy/halloysite nanotubes nanocomposite coatings: Exploring low-concentration threshold for flammability compared to expandable graphite as superior fire retardant, 119 (2018) 8-14.

[71] H. Vahabi, R. Sonnier, B. Otazaghine, G. Saout, J.J.P. Lopez-Cuesta, Nanocomposites of polypropylene/polyamide 6 blends based on three different nanoclays: thermal stability and flame retardancy, 58 (2013) 350-360.

[72] P. Rybiński, G.J.T.a. Janowska, Thermal properties and flammability of nanocomposites based on nitrile rubbers and activated halloysite nanotubes and carbon nanofibers, 549 (2012) 6-12. 
[73] L. Li, Z. Wu, S. Jiang, S. Zhang, S. Lu, W. Chen, B. Sun, M.J.P.C. Zhu, Effect of halloysite nanotubes on thermal and flame retardant properties of polyamide 6/melamine cyanurate composites, 36 (2015) 892896.

[74] P. Rybiński, G.J.T.a. Janowska, Influence synergetic effect of halloysite nanotubes and halogen-free flame-retardants on properties nitrile rubber composites, 557 (2013) 24-30.

[75] B. Lecouvet, M. Sclavons, C. Bailly, S.J.P.d. Bourbigot, stability, A comprehensive study of the synergistic flame retardant mechanisms of halloysite in intumescent polypropylene, 98 (2013) 22682281.

[76] T. Zheng, X.J.R.A. Ni, Loading an organophosphorous flame retardant into halloysite nanotubes for modifying UV-curable epoxy resin, 6 (2016) 57122-57130.

[77] J. Zhao, C.L. Deng, S.L. Du, L. Chen, C. Deng, Y.Z.J.J.o.A.P.S. Wang, Synergistic flame-retardant effect of halloysite nanotubes on intumescent flame retardant in LDPE, 131 (2014).

[78] Y. Wang, C. Liu, X. Shi, J. Liang, Z. Jia, G.J.P.C. Shi, Synergistic effect of halloysite nanotubes on flame resistance of intumescent flame retardant poly (butylene succinate) composites.

[79] W. Sun, W. Tang, X. Gu, S. Zhang, J. Sun, H. Li, X.J.J.o.A.P.S. Liu, Synergistic effect of kaolinite/halloysite on the flammability and thermostability of polypropylene, 135 (2018) 46507.

[80] R. Anyszka, D.M. Bieliński, Z. Pędzich, P. Rybiński, M. Imiela, M. Siciński, M. Zarzecka-Napierała, T. Gozdek, P.J.M. Rutkowski, Thermal stability and flammability of styrene-butadiene rubber-based (SBR) ceramifiable composites, 9 (2016) 604.

[81] N.A. Isitman, M. Dogan, E. Bayramli, C.J.P.d. Kaynak, stability, The role of nanoparticle geometry in flame retardancy of polylactide nanocomposites containing aluminium phosphinate, 97 (2012) 12851296.

[82] J. Sun, X. Gu, M. Coquelle, S. Bourbigot, S. Duquesne, M. Casetta, S.J.P.f.A.T. Zhang, Effects of melamine polyphosphate and halloysite nanotubes on the flammability and thermal behavior of polyamide 6, 25 (2014) 1552-1559.

[83] W. Tang, S. Zhang, X. Gu, J. Sun, X. Jin, H.J.A.C.S. Li, Effects of kaolinite nanoroll on the flammability of polypropylene nanocomposites, 132 (2016) 579-588.

[84] A. Gibson, W. Wan-Jusoh, G.J.P.D. Kotsikos, Stability, A propane burner test for passive fire protection (PFP) formulations containing added halloysite, carbon nanotubes and graphene, 148 (2018) 86-94.

[85] B.H. Cipiriano, T. Kashiwagi, S.R. Raghavan, Y. Yang, E.A. Grulke, K. Yamamoto, J.R. Shields, J.F.J.P. Douglas, Effects of aspect ratio of MWNT on the flammability properties of polymer nanocomposites, 48 (2007) 6086-6096.

[86] L. Dumazert, R.J.P. Sonnier, An Insight into the Flammability of Some Bio-Based Polyesters, 9 (2017) 706.

[87] Y. Lvov, W. Wang, L. Zhang, R.J.A.M. Fakhrullin, Halloysite clay nanotubes for loading and sustained release of functional compounds, 28 (2016) 1227-1250.

[88] Z. Zhang, W. Xu, L. Yuan, Q. Guan, G. Liang, A.J.J.o.A.P.S. Gu, Flame-retardant cyanate ester resin with suppressed toxic volatiles based on environmentally friendly halloysite nanotube/graphene oxide hybrid, 135 (2018) 46587. 
[89] Y. Dong, B. Lisco, H. Wu, J.H. Koo, M.J.J.o.A.P.S. Krifa, Flame retardancy and mechanical properties of ferrum ammonium phosphate-halloysite/epoxy polymer nanocomposites, 132 (2015).

[90] M. Massaro, G. Cavallaro, C.G. Colletti, G. Lazzara, S. Milioto, R. Noto, S.J.J.o.M.C.B. Riela, Chemical modification of halloysite nanotubes for controlled loading and release, 6 (2018) 3415-3433.

[91] W. Ma, H. Wu, Y. Higaki, A.J.T.C.R. Takahara, Halloysite Nanotubes: Green Nanomaterial for Functional Organic-Inorganic Nanohybrids, (2018).

[92] Y. Yang, Y. Chen, F. Leng, L. Huang, Z. Wang, W.J.A.S. Tian, Recent advances on surface modification of halloysite nanotubes for multifunctional applications, 7 (2017) 1215.

[93] H.J.N.R. Zhang, Selective modification of inner surface of halloysite nanotubes: a review, 6 (2017) 573-581.

[94] M. Massaro, C. Colletti, G. Lazzara, S. Milioto, R. Noto, S.J.J.o.M.C.A. Riela, Halloysite nanotubes as support for metal-based catalysts, 5 (2017) 13276-13293.

[95] M. Hanif, F. Jabbar, S. Sharif, G. Abbas, A. Farooq, M.J.C.M. Aziz, Halloysite nanotubes as a new drug-delivery system: a review, 51 (2016) 469-477.

[96] P. Yuan, D. Tan, F.J.A.C.S. Annabi-Bergaya, Properties and applications of halloysite nanotubes: recent research advances and future prospects, 112 (2015) 75-93.

[97] L. Fan, B. Li, Q. Wang, A. Wang, J.J.A.M.I. Zhang, Superhydrophobic gated polyorganosilanes/halloysite nanocontainers for sustained drug release, 1 (2014) 1300136.

[98] R.S. Hebbar, A.M. Isloor, A. Zulhairun, M.S. Abdullah, A.J.J.o.t.T.I.o.C.E. Ismail, Efficient treatment of hazardous reactive dye effluents through antifouling polyetherimide hollow fiber membrane embedded with functionalized halloysite nanotubes, 72 (2017) 244-252.

[99] S. Das, S.J.E.S.N. Jana, A tubular nanoreactor directing the formation of in situ iron oxide nanorods with superior photocatalytic activity, 4 (2017) 596-603.

[100] R. Berahman, M. Raiati, M.M. Mazidi, S.M.R.J.M. Paran, Design, Preparation and characterization of vulcanized silicone rubber/halloysite nanotube nanocomposites: Effect of matrix hardness and HNT content, 104 (2016) 333-345.

[101] E. Bischoff, D. Simon, H. Schrekker, M. Lavorgna, L. Ambrosio, S. Liberman, R.J.E.P.J. Mauler, lonic liquid tailored interfaces in halloysite nanotube/heterophasic ethylene-propylene copolymer nanocomposites with enhanced mechanical properties, 82 (2016) 82-92.

[102] M.R. Dzamukova, E.A. Naumenko, Y.M. Lvov, R.F.J.S.r. Fakhrullin, Enzyme-activated intracellular drug delivery with tubule clay nanoformulation, 5 (2015) 10560.

[103] G. Cavallaro, G. Lazzara, S. Milioto, F.J.L. Parisi, Hydrophobically modified halloysite nanotubes as reverse micelles for water-in-oil emulsion, 31 (2015) 7472-7478.

[104] H. Lun, J. Ouyang, H.J.P. Yang, C.o. Minerals, Enhancing dispersion of halloysite nanotubes via chemical modification, 41 (2014) 281-288.

[105] Z. Liu, Z. Mi, S. Jin, C. Wang, D. Wang, X. Zhao, H. Zhou, C.J.J.o.M.S. Chen, The influence of sulfonated hyperbranched polyethersulfone-modified halloysite nanotubes on the compatibility and water separation performance of polyethersulfone hybrid ultrafiltration membranes, 557 (2018) 13-23.

[106] W.R. Grimes, Y. Luo, A.W. McFarland, D.K.J.A.S. Mills, Bi-Functionalized Clay Nanotubes for AntiCancer Therapy, 8 (2018) 281. 
[107] N. Bahri-Laleh, S. Sadjadi, M.M. Heravi, M.J.A.O.C. Malmir, Cul-functionalized halloysite nanoclay as an efficient heterogeneous catalyst for promoting click reactions: Combination of experimental and computational chemistry, 32 (2018) e4283.

[108] J. Kurczewska, M. Cegłowski, B. Messyasz, G.J.A.C.S. Schroeder, Dendrimer-functionalized halloysite nanotubes for effective drug delivery, 153 (2018) 134-143.

[109] J. Lin, Y. Luo, B. Zhong, D. Hu, Z. Jia, D.J.A.S.S. Jia, Enhanced interfacial interaction and antioxidative behavior of novel halloysite nanotubes/silica hybrid supported antioxidant in styrenebutadiene rubber, 441 (2018) 798-806.

[110] M. Malmir, M.M. Heravi, S. Sadjadi, T.J.A.O.C. Hosseinnejad, Ultrasonic and bio-assisted synthesis of Ag@ HNTs-T as a novel heterogeneous catalyst for the green synthesis of propargylamines: A combination of experimental and computational study, 32 (2018) e4291.

[111] S. Sadjadi, M.M. Heravi, M. Malmir, B.J.A.O.C. Masoumi, HPA decorated Halloysite Nanoclay: An efficient catalyst for the green synthesis of Spirooxindole derivatives, 32 (2018) e4113.

[112] M. Massaro, A. Campofelice, C.G. Colletti, G. Lazzara, R. Noto, S.J.A.C.S. Riela, Functionalized halloysite nanotubes: Efficient carrier systems for antifungine drugs, 160 (2018) 186-192.

[113] M. Sahnoune, A. Taguet, B. Otazaghine, M. Kaci, J.M.J.P.I. Lopez-Cuesta, Inner surface modification of halloysite nanotubes and its influence on morphology and thermal properties of polystyrene/polyamide-11 blends, 66 (2017) 300-312.

[114] L. Noein, V. Haddadi-Asl, M.J.I.J.o.P.M. Salami-Kalajahi, P. Biomaterials, Grafting of pH-sensitive poly ( $\mathrm{N}, \mathrm{N}$-dimethylaminoethyl methacrylate-co-2-hydroxyethyl methacrylate) onto HNTS via surfaceinitiated atom transfer radical polymerization for controllable drug release, 66 (2017) 123-131.

[115] L.G. Bach, V.T.T. Ho, B.T.P. Quynh, K.T. Lim, T.C.J.J.o.N. Anh, Nanotechnology, Synthesis of WellDefined Amphiphilic Diblock Copolymer Brushes on Halloysite Nanotubes via Surface-Initiated Reversible Addition-Fragmentation Chain Transfer Polymerization, 17 (2017) 5834-5838.

[116] K. Buruga, J.T.J.J. Kalathi, Fabrication of $\mathrm{Y}$-MPS-Modified HNT-PMMA Nanocomposites by Ultrasound-Assisted Miniemulsion Polymerization, (2018) 1-6.

[117] A. Maleki, Z. Hajizadeh, R.J.M. Firouzi-Haji, M. Materials, Eco-friendly functionalization of magnetic halloysite nanotube with SO3H for synthesis of dihydropyrimidinones, 259 (2018) 46-53.

[118] A.A. Kadam, J. Jang, S.C. Jee, J.-S. Sung, D.S.J.C.p. Lee, Chitosan-functionalized supermagnetic halloysite nanotubes for covalent laccase immobilization, 194 (2018) 208-216.

[119] Y. Liu, J. Zhang, H. Guan, Y. Zhao, J.-H. Yang, B.J.A.S.S. Zhang, Preparation of bimetallic Cu-Co nanocatalysts on poly (diallyldimethylammonium chloride) functionalized halloysite nanotubes for hydrolytic dehydrogenation of ammonia borane, 427 (2018) 106-113.

[120] Z.U. Zango, N.H.H. Abu Bakar, W.L. Tan, M.A.J.J.o.D.S. Bakar, Technology, Enhanced removal efficiency of methyl red via the modification of halloysite nanotubes by copper oxide, 39 (2018) 148154.

[121] S. Farhanian, M.J.J.o.T.A. Hatami, Calorimetry, Thermal and morphological aspects of silver decorated halloysite reinforced polypropylene nanocomposites, 130 (2017) 2069-2078.

[122] T. Rostamzadeh, M.S. Islam Khan, K. Riche', Y.M. Lvov, A.V. Stavitskaya, J.B.J.L. Wiley, Rapid and Controlled In Situ Growth of Noble Metal Nanostructures within Halloysite Clay Nanotubes, 33 (2017) 13051-13059. 
[123] G. Mishra, M.J.N.J.o.C. Mukhopadhyay, Flux improvement, rejection, surface energy and antibacterial properties of synthesized TiO 2-Mo. HNTs/PVC nanocomposite ultrafiltration membranes, 41 (2017) 15049-15057.

[124] W.A. Molano, J.C. Cárdenas, C.A. Sierra, J.G. Carriazo, C.J.C. Ochoa-Puentes, Pd/Halloysite as a Novel, Efficient and Reusable Heterogeneous Nanocatalyst for the Synthesis of p-Phenylenevinylene Oligomers, 3 (2018) 4430-4438.

[125] M. Viseras, C. Aguzzi, P. Cerezo, C. Viseras, C.J.M. Valenzuela, m. materials, Equilibrium and kinetics of 5-aminosalicylic acid adsorption by halloysite, 108 (2008) 112-116.

[126] S. Mellouk, S. Cherifi, M. Sassi, K. Marouf-Khelifa, A. Bengueddach, J. Schott, A.J.A.C.S. Khelifa, Intercalation of halloysite from Djebel Debagh (Algeria) and adsorption of copper ions, 44 (2009) 230236.

[127] S. Levis, P.J.I.j.o.p. Deasy, Use of coated microtubular halloysite for the sustained release of diltiazem hydrochloride and propranolol hydrochloride, 253 (2003) 145-157.

[128] E. Abdullayev, A. Joshi, W. Wei, Y. Zhao, Y.J.A.n. Lvov, Enlargement of halloysite clay nanotube lumen by selective etching of aluminum oxide, 6 (2012) 7216-7226.

[129] Y. Lvov, E.J.P.i.P.S. Abdullayev, Functional polymer-clay nanotube composites with sustained release of chemical agents, 38 (2013) 1690-1719.

[130] B. Lecouvet, M. Sclavons, S. Bourbigot, C.J.P.f.A.T. Bailly, Towards scalable production of polyamide 12/halloysite nanocomposites via water-assisted extrusion: mechanical modeling, thermal and fire properties, 25 (2014) 137-151.

[131] V.A. Vinokurov, A.V. Stavitskaya, A.P. Glotov, A.A. Novikov, A.V. Zolotukhina, M.S. Kotelev, P.A. Gushchin, E.V. Ivanov, Y. Darrat, Y.M.J.T.C.R. Lvov, Nanoparticles Formed Onto/Into Halloysite Clay Tubules: Architectural Synthesis and Applications, (2018).

[132] W.O. Yah, A. Takahara, Y.M.J.J.o.t.A.C.S. Lvov, Selective modification of halloysite lumen with octadecylphosphonic acid: new inorganic tubular micelle, 134 (2012) 1853-1859.

[133] D. Marney, W. Yang, L. Russell, S. Shen, T. Nguyen, Q. Yuan, R. Varley, S.J.P.f.A.T. Li, Phosphorus intercalation of halloysite nanotubes for enhanced fire properties of polyamide 6, 23 (2012) 1564-1571.

[134] M. Sahnoune, A. Taguet, B. Otazaghine, M. Kaci, J.M.J.P.E. Lopez-Cuesta, Science, Fire retardancy effect of phosphorus-modified halloysite on polyamide-11 nanocomposites, (2018).

[135] Z. Li, D.F. Expósito, A.J. González, D.-Y.J.E.P.J. Wang, Natural halloysite nanotube based functionalized nanohybrid assembled via phosphorus-containing slow release method: A highly efficient way to impart flame retardancy to polylactide, 93 (2017) 458-470.

[136] H. Jing, Y. Higaki, W. Ma, H. Wu, W.O. Yah, H. Otsuka, Y.M. Lvov, A.J.C.I. Takahara, Internally modified halloysite nanotubes as inorganic nanocontainers for a flame retardant, 42 (2013) 121-123.

[137] M.J.F. Lewin, materials, Some comments on the modes of action of nanocomposites in the flame retardancy of polymers, 27 (2003) 1-7.

[138] R. El Hage, A. Viretto, R. Sonnier, L. Ferry, J.-M.J.P.D. Lopez-Cuesta, Stability, Flame retardancy of ethylene vinyl acetate (EVA) using new aluminum-based fillers, 108 (2014) 56-67. 